\title{
Toward the Decentralized Electrochemical Production of H2O2: A Focus on the Catalysis
}

Yang, Sungeun; Verdaguer Casadevall, Arnau; Arnarson, Logi; Silvioli, Luca; oli, Viktor; Frydendal, Rasmus; Rossmeisl, Jan; Chorkendorff, Ib; Stephens, Ifan E. L.

Published in:

A C S Catalysis

Link to article, DOI:

10.1021/acscatal.8b00217

Publication date:

2018

Document Version

Peer reviewed version

Link back to DTU Orbit

Citation (APA):

Yang, S., Verdaguer Casadevall, A., Arnarson, L., Silvioli, L., oli, V., Frydendal, R., Rossmeisl, J., Chorkendorff, I., \& Stephens, I. E. L. (2018). Toward the Decentralized Electrochemical Production of $\mathrm{H}_{2} \mathrm{O}_{2}$ : A Focus on the Catalysis. A C S Catalysis, 8, 4064-4081. https://doi.org/10.1021/acscatal.8b00217

\section{General rights}

Copyright and moral rights for the publications made accessible in the public portal are retained by the authors and/or other copyright owners and it is a condition of accessing publications that users recognise and abide by the legal requirements associated with these rights.

- Users may download and print one copy of any publication from the public portal for the purpose of private study or research.

- You may not further distribute the material or use it for any profit-making activity or commercial gain

- You may freely distribute the URL identifying the publication in the public portal 


\section{Towards the decentralized electrochemical}

\section{production of $\mathrm{H}_{2} \mathrm{O}_{2}$ : A focus on the catalysis}

Sungeun Yang, Arnau Verdaguer-Casadevall,, Logi Arnarson, Luca Silvioli,, Viktor Čolić,

Rasmus Frydendal, ${ }^{,}$Jan Rossmeisl,,${ }^{\prime}$ Ib Chorkendorff, and Ifan E. L. Stephens ${ }^{* *}, \|$

Section for Surface Physics and Catalysis, Department of Physics, Technical University of

Denmark, Kongens Lyngby, DK-2800, Denmark

HPNow, Ole Maaløes Vej 3, Copenhagen N, DK-2200, Denmark

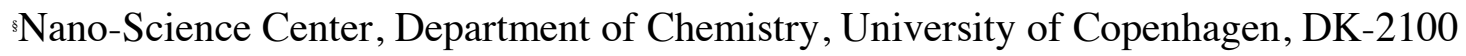

Copenhagen $\emptyset$, Denmark

"Department of Materials, Imperial College London, London, SW7 2AZ, United Kingdom 


\begin{abstract}
$\mathrm{H}_{2} \mathrm{O}_{2}$ is a valuable, environmentally friendly oxidizing agent, with a wide range of uses, from the provision of clean water to the synthesis of valuable chemicals. The on-site electrolytic production of $\mathrm{H}_{2} \mathrm{O}_{2}$ would bring the chemical to applications beyond its present reach. The successful commercialization of electrochemical $\mathrm{H}_{2} \mathrm{O}_{2}$ production requires cathode catalysts with high activity, selectivity and stability. In this Perspective, we highlight our current understanding of the factors that control the cathode performance. We review the influence of catalyst material, electrolyte and the structure of the interface at the mesoscopic scale. We provide original theoretical data on the role of the geometry of the active site and its influence on activity and selectivity. We have also conducted a series of original experiments on (i) the effect of $\mathrm{pH}$ on $\mathrm{H}_{2} \mathrm{O}_{2}$ production on glassy carbon, pure metals, and metal-mercury alloys, and (ii) the influence of cell geometry and mass transport in liquid half-cells in comparison to membrane electrode assemblies.
\end{abstract}

\title{
KEYWORDS
}

Hydrogen peroxide, electrocatalysis, oxygen reduction reaction, catalyst selectivity, power-tochemicals, electrochemical synthesis, geometric effects, electronic effects. 


\section{INTRODUCTION; Current status of $\mathrm{H}_{2} \mathrm{O}_{2}$ production}

$\mathrm{H}_{2} \mathrm{O}_{2}$ is a versatile and environmentally friendly oxidant. It plays a critical role in a remarkably diverse range of applications, including first-aid kits for disinfection, pulp and textile bleaching,' wastewater treatment, ${ }^{2}$ chemical synthesis, ${ }^{3-5}$ semiconductor cleaning, detergent, and exhaust air treatment (Figure $\left.1^{\circ}\right)$. Increased efforts to avoid environmental damage are driving an upswing in demand for $\mathrm{H}_{2} \mathrm{O}_{2} \cdot$. The annual production of $\mathrm{H}_{2} \mathrm{O}_{2}$ reached 5.5 million $\mathrm{t}^{\mathrm{t}}$ in 2015 , significantly exceeding the forecast of 4.3 million $\mathrm{t}$ made in 2011.

In this Perspective, we summarize the established anthraquinone method for industrial $\mathrm{H}_{2} \mathrm{O}_{2}$ production along with upcoming alternatives, such as direct synthesis and electrochemical synthesis. We review past literature and present new experimental and theoretical data; on this basis, we argue that successful implementation of electrochemical $\mathrm{H}_{2} \mathrm{O}_{2}$ production can be realized by carefully tailoring the electrode and electrolyte at the cathode of electrochemical cells.

Anthraquinone process. The anthraquinone process (sometimes known as the auto-oxidation process), was a breakthrough in the large-scale production of hydrogen peroxide. It quickly

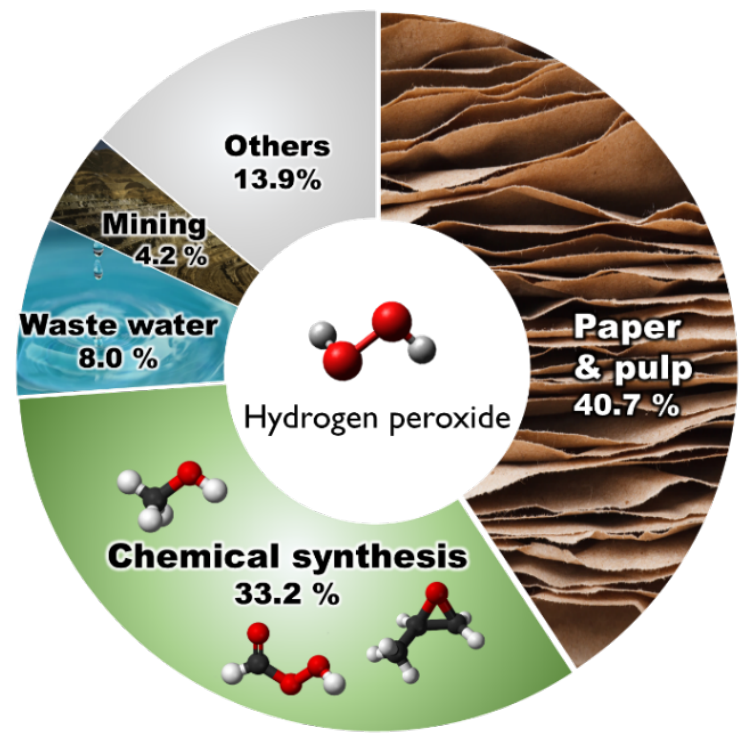

Figure 1. Market share of hydrogen peroxide in USA, 2015 . 
became the most used process after its development in 1939 by Riedl and Pfleiderer, , and the first successful production plant came into use in $1953 .^{10}$ It is still the most widely used process and accounts for more than $95 \%$ of $\mathrm{H}_{2} \mathrm{O}_{2}$ production today. ${ }^{8}$ It consists of sequential hydrogenation and oxidation steps in an organic solvent, followed by extraction and further distillation, as shown in Figure 2. An anthraquinone derivative, usually 2-alkyl anthraquinone, is used as a reaction carrier. The anthraquinone molecule is first hydrogenated to corresponding hydroquinone under hydrogen with $\mathrm{Ni}$ or supported $\mathrm{Pd}$ as catalyst. After separation, hydroquinone is oxidized with air to produce $\mathrm{H}_{2} \mathrm{O}_{2}$ along with anthraquinone molecule. Subsequently, $\mathrm{H}_{2} \mathrm{O}_{2}$ is extracted from the organic solvent by water to produce an aqueous solution of $\mathrm{H}_{2} \mathrm{O}_{2}$. Distillation follows to produce concentrated $\mathrm{H}_{2} \mathrm{O}_{2}$ solution. Anthraquinone molecules in the organic solvent are regenerated and reused in the next cycle."

The major drawbacks of the anthraquinone process are that it requires large infrastructure and that it is a batch method. The large-scale, centralized, production requires additional transportation of a hazardous material. To minimize transportation costs, energy-intensive distillation is required to produce up to $70 \mathrm{wt} \% \mathrm{H}_{2} \mathrm{O}_{2}$. Nonetheless, there are multiple applications where end-users require dilute $\mathrm{H}_{2} \mathrm{O}_{2}$ solutions. Many applications require $<9 \mathrm{wt} \%$ of $\mathrm{H}_{2} \mathrm{O}_{2}$, such as pulp bleaching, chemical

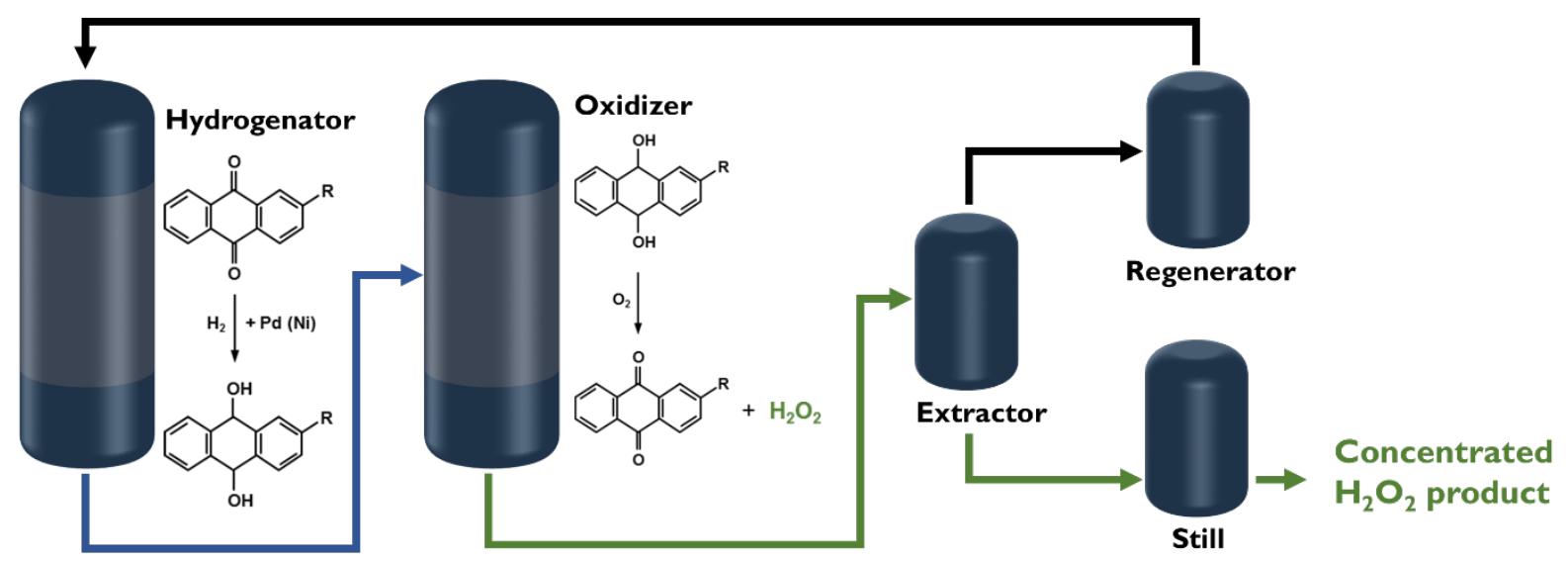

Figure 2. Schematic of anthraquinone process 
synthesis, medical uses, and cosmetic uses..$^{12-14}$ On the other hand, for water treatment, only $<0.1$ wt $\% \mathrm{H}_{2} \mathrm{O}_{2}$ is necessary. ${ }^{15}$ Highly concentrated $\mathrm{H}_{2} \mathrm{O}_{2}$ is explosive, and its transportation has caused severe accidents, exemplified by incidents in Helena, Montana, USA in $1989^{16}$ and in London, England in 2005.7 Moreover, care must be taken when diluting concentrated $\mathrm{H}_{2} \mathrm{O}_{2}$. Other drawbacks of the anthraquinone process include (i) the use of large amounts of organic solvents (ii) the degradation of anthraquinone molecules (iii) the need to add stabilizer to prevent the decomposition of concentrated $\mathrm{H}_{2} \mathrm{O}_{2}$; stabilizers can be undesirable for many consumers, meaning that they need to be tailored for specific applications and industries..$^{14}$ The deficiencies of the anthraquinone process are motivating industry and academia alike to develop alternative synthesis methods, thus decentralizing $\mathrm{H}_{2} \mathrm{O}_{2}$ production, in particular the direct synthesis and electrochemical methods. Despite the differences between the two methods, they do share similar attributes, especially in terms of the catalysis. Therefore, we will introduce the factors controlling the catalysis of the direct synthesis method, before focusing on electrochemical $\mathrm{H}_{2} \mathrm{O}_{2}$ production.

\section{DIRECT SYNTHESIS OF $\mathrm{H}_{2} \mathrm{O}_{2}$}

The direct synthesis of $\mathrm{H}_{2} \mathrm{O}_{2}$ is a straightforward batch process, where both $\mathrm{H}_{2}$ and $\mathrm{O}_{2}$ gases are simultaneously introduced into a liquid medium in the presence of a catalyst (Figure 3). It was first reported as early as $1914 .{ }^{18}$ It avoids the need to transport $\mathrm{H}_{2} \mathrm{O}_{2}$ to site, but does require $\mathrm{H}_{2}$. Because it involves a mixture of $\mathrm{H}_{2}$ and $\mathrm{O}_{2}$, these gases are diluted in $\mathrm{N}_{2}$ or $\mathrm{CO}_{2}$ to avoid entering the flammable range; such dilution limits the productivity of the process..$^{19}$

$\mathrm{H}_{2} \mathrm{O}_{2}$ production comprises the selective hydrogenation of $\mathrm{O}_{2}$ (Figure $4 \mathrm{a}$ ). The role of the catalyst should be to sustain high rates of $\mathrm{H}_{2} \mathrm{O}_{2}$ production while minimizing its further reduction to $\mathrm{H}_{2} \mathrm{O}$. It 


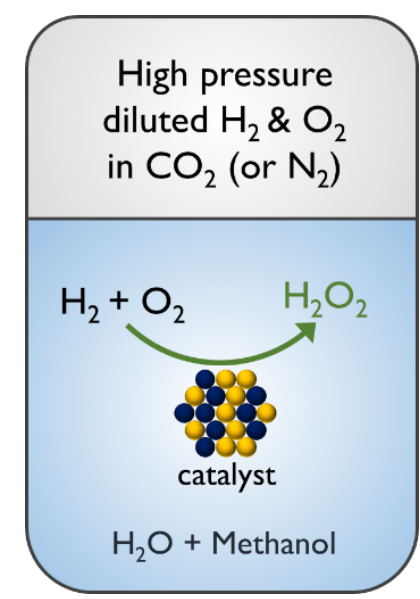

Figure 3. Schematic of direct synthesis of $\mathrm{H}_{2} \mathrm{O}_{2}$

should also prevent $\mathrm{H}_{2} \mathrm{O}_{2}$ decomposition. Most experiments have focused on $\mathrm{Pd}$, or Pd-based catalysts; ${ }^{1202022}$ in particular Hutchings and coworkers have produced seminal works in this area, on Pd-Au and Pd-Sn catalysts. ${ }^{12,1921223-27}$

The proposed mechanism for direct synthesis is as follows: the reaction starts with a $\mathrm{H}_{2}$ molecule dissociating into hydrogen atoms on the catalyst surface. Subsequently, an $\mathrm{O}_{2}$ molecule adsorbs on the catalyst surface and react with hydrogen atom to form $* \mathrm{OOH}$ intermediate. The $* \mathrm{OOH}$ intermediate reacts with another hydrogen atom to form $\mathrm{H}_{2} \mathrm{O}_{2}$, followed by desorption of $\mathrm{H}_{2} \mathrm{O}_{2}$ from the catalyst surface. ${ }^{8,202428}$

Density functional theory (DFT) calculations reveal the electronic factors that control the direct synthesis of $\mathrm{H}_{2} \mathrm{O}_{2}{ }^{28,29}$ Rankin and Greeley showed that the activity and selectivity of the direct synthesis is controlled by the binding energies of $* \mathrm{O}$ and $* \mathrm{H}$ (where $*$ denotes species adsorbed onto an active surface site), as shown in the volcano on Figure $4 b .^{28}$ The contour map of Figure $4 b$ represents the predicted activity for $\mathrm{O}_{2}$ reduction; it is based on Sabatier's principle, which states that the optimal catalyst should exhibit intermediate binding to the reaction intermediates. The reason that such a complicated reaction can be described solely by the binding energies of *O and ${ }^{*} \mathrm{H}$ is that the binding energies of the other adsorbed intermediates, such as $* \mathrm{OH}$ and $* \mathrm{OOH}$, scale 
linearly with that of $* \mathrm{O}$. Thus, metals that exhibit strong binding to $* \mathrm{O}$ and $* \mathrm{H}-$ such as $\mathrm{Ru}, \mathrm{Rh}$, $\mathrm{Ni}, \mathrm{Co}, \mathrm{Os}$, and $\mathrm{Rh}-$ are rate limited by the hydrogenation of $* \mathrm{OH}$. Conversely, metals on the upper side of the volcano, which exhibit weak binding to ${ }^{*} \mathrm{H}-$ such as $\mathrm{Au}$ and $\mathrm{Ag}$ - are rate limited by the dissociation of $\mathrm{H}_{2}$. No pure metals occupy the lower right side of the volcano, which is limited by $\mathrm{O}_{2}$ dissociation and $* \mathrm{OOH}$ formation. Other metals - such as $\mathrm{Pd}, \mathrm{Pt}, \mathrm{Cu}$ or $\mathrm{Ir}-$ intersect different rate-limiting steps and exhibit the highest activity, hence occupying the peak of the volcano. Not only are these catalysts highly active for $\mathrm{O}_{2}$ reduction to $\mathrm{H}_{2} \mathrm{O}_{2}$, but also for the further reduction to $\mathrm{H}_{2} \mathrm{O}$. Consequently, additional criteria are required to identify the most selective catalysts: in particular, they should disfavor the dissociation of the species, $\mathrm{O}_{2}, * \mathrm{OOH}$, and $\mathrm{H}_{2} \mathrm{O}_{2}$ relative to the desired hydrogenation steps. Such surfaces would occupy the shaded area on the right-hand side of the volcano on Figure $4 \mathrm{~b}$. The only pure metal to occupy this shaded area is Au. Notably, Figure 4b are modelled by terraces. More realistically, the surfaces of nanoparticles contain steps and edges, which would favor $\mathrm{O}-\mathrm{O}$ dissociation, further shrinking the peroxide selectivity window.

The optimal catalyst should have slightly stronger binding energies of $* \mathrm{O}$ and $* \mathrm{H}$ than $\mathrm{Au}$, while remaining in the selective grey region in Figure 4b. It turns out that AuPd alloys fit these criteria, explaining the experimental interest in these alloys.

According to Hutchings and coworkers, AuPd alloy catalysts exhibit higher $\mathrm{H}_{2} \mathrm{O}_{2}$ production rates than pure $\mathrm{Pd}$ or pure $\mathrm{Au}$, in agreement with the theoretical model in Figure $4 \mathrm{~b} .^{23}$ Figure 5 shows high-angle annular dark-field scanning transmission electron microscopy (HAADF-STEM) images and elemental mapping of calcined AuPd catalysts on three different supports: $\mathrm{C}, \mathrm{TiO}_{2}$ and $\mathrm{Al}_{2} \mathrm{O}_{3}{ }^{25}$ The most active and selective catalyst, $\mathrm{AuPd} / \mathrm{C}$, consisted of a homogeneous alloy of AuPd, while the other two catalysts consisted of a Au core with a Pd shell. ${ }^{25}$ Curiously, they found the 
(a)

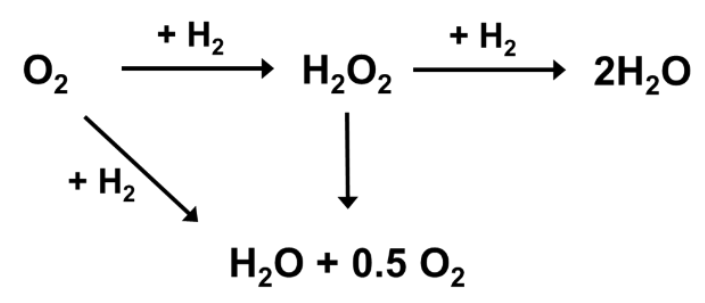

(b)

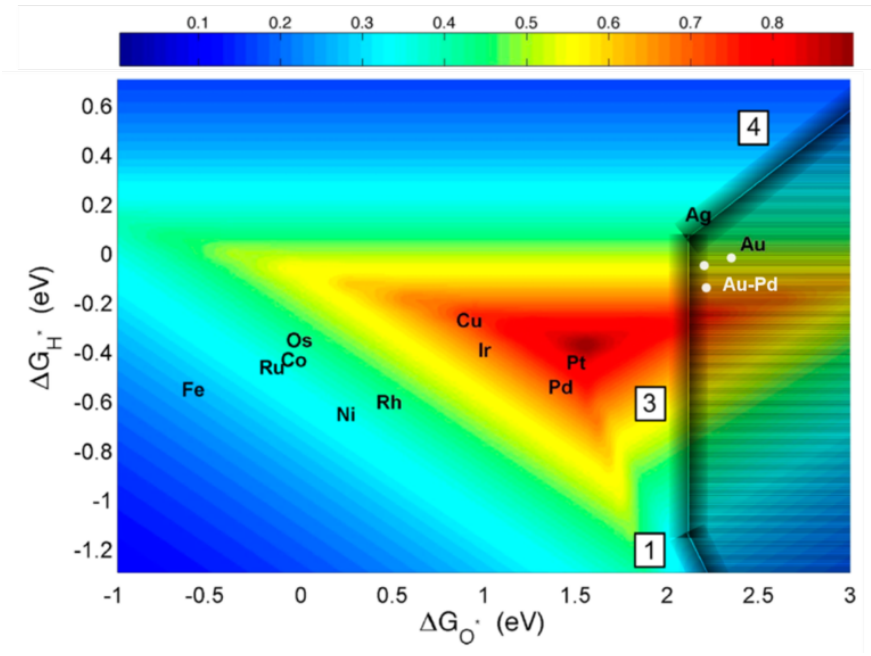

Figure 4. (a) Reaction pathways for direct synthesis of $\mathrm{H}_{2} \mathrm{O}_{2}$. (b) Activity contour map and $\mathrm{H}_{2} \mathrm{O}_{2}$ selective boundaries on 12 transition metal surfaces and three different $\mathrm{Pd}-\mathrm{Au}$ surfaces for direct synthesis of $\mathrm{H}_{2} \mathrm{O}_{2}$. White dots, clockwise from top, represent $\mathrm{Pd} / / \mathrm{Au}_{2} \mathrm{Pd}_{2} / \mathrm{Au}_{2} \mathrm{Pd}_{2} / \mathrm{Au}_{4}$, $\mathrm{Pd}_{2} \mathrm{Au}_{3} / \mathrm{Pd}_{2} \mathrm{Au}_{2} / \mathrm{Pd}_{2} \mathrm{Au}_{2} / \mathrm{Pd}_{2} \mathrm{Au}_{2}$, and $\mathrm{Pd}_{4} / \mathrm{Au}_{2} \mathrm{Pd}_{2} / \mathrm{AuPd}_{3} / \mathrm{Au}_{4}$. Activity volcano contour for direct oxygen reduction is shown in eV, normalized by $k_{B} T / h$. Selective $\mathrm{H}_{2} \mathrm{O}_{2}$ formation is represented by the grey region. Lines represents competition between (1) $\mathrm{O}_{2}$ hydrogenation and dissociation, (3) $\mathrm{H}_{2} \mathrm{O}_{2}$ desorption and dissociation, and (4) $\mathrm{OOH}$ hydrogenation and dissociation. Free energies of oxygen and hydrogen adsorption are denoted as $\Delta G_{\circ^{\circ}}$ and $\Delta G_{н}$. Adapted with permission from Ref ${ }^{28}$. Copyright 2012 American Chemical Society.

carbon support alone to be highly active for the unwant ed reaction, $\mathrm{H}_{2} \mathrm{O}_{2}$ hydrogenation. They proposed that the introduction of Au affects the selectivity by blocking impurity sites on the surface 
of the carbon that are responsible for $\mathrm{H}_{2} \mathrm{O}_{2}$ decomposition. ${ }^{21}$ This significant finding suggests that controlling selectivity is complex; the factors controlling it cannot be entirely described by the simple Sabatier volcano model depicted by Figure $4 \mathrm{~b}$.

Freakley et al. showed that the addition of Sn to Pd catalysts also improves their activity and selectivity for the direct synthesis of $\mathrm{H}_{2} \mathrm{O}_{2}{ }^{22}$ The two metals formed homogeneous alloy nanoparticles, with some coverage of surface $\mathrm{SnO}_{x}$. Presumably, $\mathrm{Sn}$ has a similar electronic effect to $\mathrm{Au}$ in improving the activity of $\mathrm{Pd}$. On the other hand, they suggested that the improved selectivity was due to the encapsulation of small Pd nanoparticles, which would typically catalyse the further hydrogenation.

Halide ions and acid promoters are added to prevent further hydrogenation of $\mathrm{H}_{2} \mathrm{O}_{2}$ on $\mathrm{Pd}$ catalysts. Halide anions, especially $\mathrm{Cl}$ and $\mathrm{Br}$, act as a poisoning species and decrease overall activity while increasing $\mathrm{H}_{2} \mathrm{O}_{2}$ selectivity. Burch et al. clearly showed the halide effect in direct synthesis using different concentration of $\mathrm{NaBr}$ promoter on $\mathrm{Pd} / \mathrm{C}$ catalyst. ${ }^{30}$ There is no $\mathrm{H}_{2} \mathrm{O}_{2}$ production in the absence of $\mathrm{Br}$; however, upon addition of $\mathrm{Br}, \mathrm{H}_{2} \mathrm{O}_{2}$ starts being produced. $\mathrm{H}_{2} \mathrm{O}_{2}$ yields increase with increasing concentration of $\mathrm{Br}$, at the expense of lower hydrogen conversion. However, at high concentrations, Br blocks surface active sites and both $\mathrm{H}_{2}$ conversion and $\mathrm{H}_{2} \mathrm{O}_{2}$ yield drastically diminish. Other researchers also observed halide effect on direct synthesis. ${ }^{26,31-33}$ The addition of acid can increase the stability of $\mathrm{H}_{2} \mathrm{O}_{2}$ since $\mathrm{H}_{2} \mathrm{O}_{2}$ decomposition is base-catalyzed. . $603032^{232}$ For this reason, the use of acidic support materials increased the $\mathrm{H}_{2} \mathrm{O}_{2}$ yield..$^{24}$ For the direct synthesis of $\mathrm{H}_{2} \mathrm{O}_{2}$, the addition of both halides and acid to Pd catalysts is commonplace. However, the subsequent need to remove these toxic additives is undesirable. 

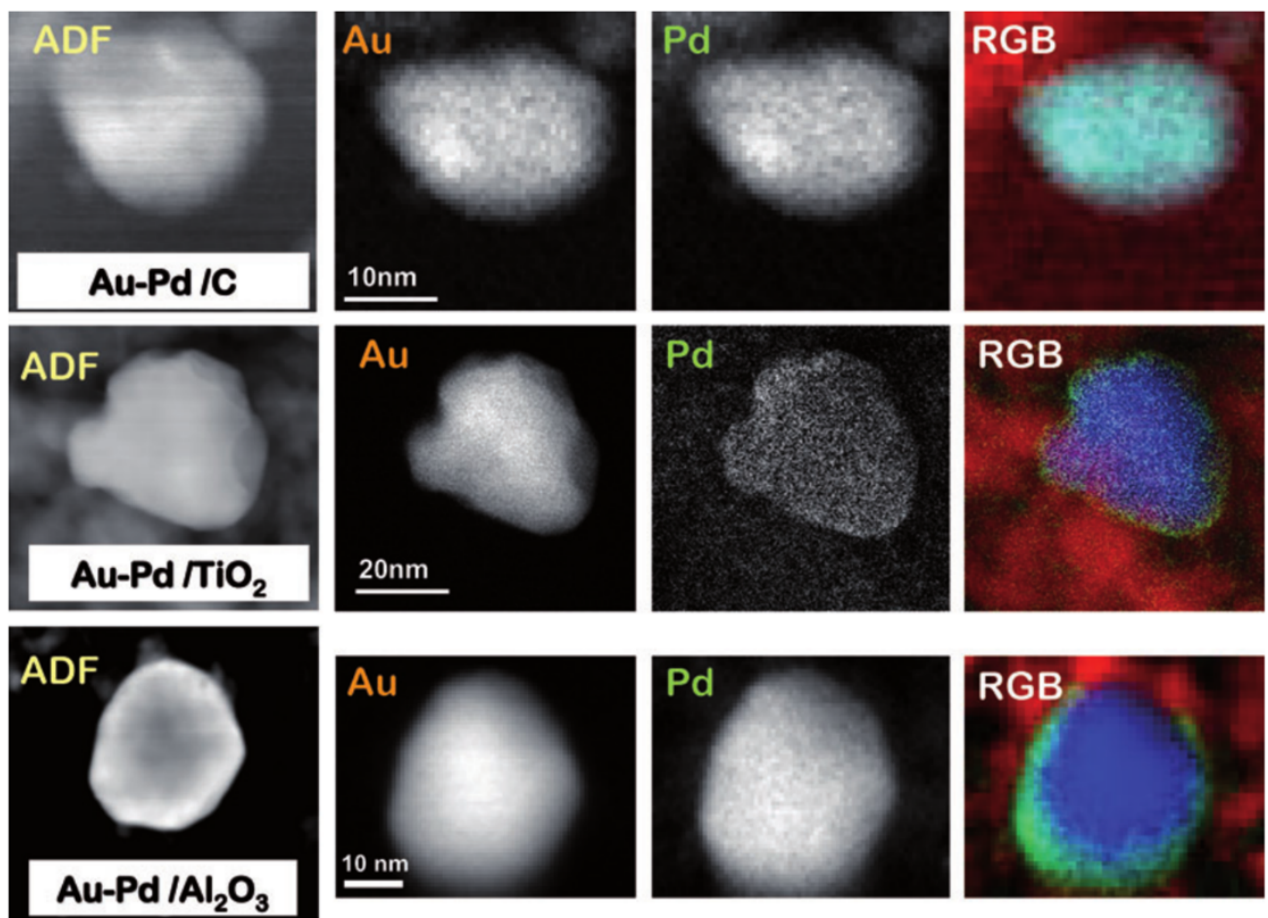

Figure 5. HAADF-STEM image (column 1), elemental mapping of Au (column 2), elemental mapping of Pd (column 3), overlay of Au (blue) and Pd (green) (column 4) for calcined $\mathrm{AuPd} / \mathrm{C}$, calcined $\mathrm{AuPd} / \mathrm{TiO}_{2}$, and calcined $\mathrm{AuPd} / \mathrm{Al}_{2} \mathrm{O}_{3}$ (row 3). Reproduced from Ref ${ }^{25}$ with permission of The Royal Society of Chemistry.

Hutchings and coworkers are implementing the direct synthesis into domestic greywater treatment systems.$^{34}$ Greywater is domestic wastewater from bathrooms, laundry, and kitchen sinks. It could be reused for flushing, gardening, and washing after on-site treatment. $\mathrm{H}_{2} \mathrm{O}_{2}$ is well suited to such applications. ${ }^{3536}$ The process would require an onsite water electrolyser to produce the $\mathrm{H}_{2}$ and $\mathrm{O}_{2}$, coupled to the direct synthesis reactor.

\section{ELECTROCHEMICAL $\mathrm{H}_{2} \mathrm{O}_{2}$ PRODUCTION}

The electrochemical production of $\mathrm{H}_{2} \mathrm{O}_{2}$ proceeds via the cathodic reduction of $\mathrm{O}_{2}$. The reaction can either produce the desired $\mathrm{H}_{2} \mathrm{O}_{2}$ via the 2-electron pathway or $\mathrm{H}_{2} \mathrm{O}$ via the 4-electron pathway 
(c.f. the direct synthesis process, on Figure 4). The overall reactions and thermodynamic potentials versus reversible hydrogen electrode (RHE) are as follows:

At $\mathrm{pH}<11.6$

$$
\begin{array}{ll}
\mathrm{O}_{2}+2 \mathrm{H}^{+}+2 \mathrm{e}^{-} \rightarrow \mathrm{H}_{2} \mathrm{O}_{2} & \left(U_{0}^{\mathrm{O}_{2} / \mathrm{H}_{2} \mathrm{O}_{2}}=0.7 \mathrm{~V} \text { vs RHE }\right) \\
\mathrm{O}_{2}+4 \mathrm{H}^{+}+4 \mathrm{e}^{-} \rightarrow \quad 2 \mathrm{H}_{2} \mathrm{O} & \left(U_{0}^{\mathrm{O}_{2} / \mathrm{H}_{2} \mathrm{O}}=1.23 \mathrm{~V} \text { vs RHE }\right)
\end{array}
$$

However, above the pKa of $\mathrm{H}_{2} \mathrm{O}_{2}$, which is 11.6, the product of the 2-electron pathway changes from $\mathrm{H}_{2} \mathrm{O}_{2}$ to $\mathrm{HO}_{2}$. Consequently, should we consider $\mathrm{pH}$ 13:

$$
\begin{array}{ll}
\mathrm{O}_{2}+\mathrm{H}_{2} \mathrm{O}+2 \mathrm{e}^{-} \rightarrow \mathrm{HO}_{2}^{-}+\mathrm{OH}^{-} & \left(U_{0}^{\mathrm{O}_{2} / \mathrm{HO}_{2}^{-}}=0.74 \mathrm{~V} \text { vs RHE }\right) \\
\mathrm{O}_{2}+2 \mathrm{H}_{2} \mathrm{O}+4 \mathrm{e}^{-} \rightarrow 4 \mathrm{OH}^{-} & \left(U_{0}^{\mathrm{O}_{2} / \mathrm{OH}-}=1.23 \mathrm{~V} \text { vs RHE }\right)
\end{array}
$$

In this article, we consider the selectivity towards $\mathrm{H}_{2} \mathrm{O}_{2}$ as the Faradaic efficiency, $\lambda_{\text {Faradaic }}$, defined as the ratio of charge converted to $\mathrm{H}_{2} \mathrm{O}_{2}$, to the total charge transferred.

Prior to the invention of anthraquinone process, electrolysis constituted the primary source of commercial $\mathrm{H}_{2} \mathrm{O}_{2}$. In 1853, Meidinger synthesized hydrogen peroxide by electrolysis of aqueous sulfuric acid. Sulfuric acid, $\mathrm{H}_{2} \mathrm{SO}_{4}$, was first oxidized to peroxodisulfuric acid, $\mathrm{H}_{2} \mathrm{~S}_{2} \mathrm{O}_{8}$, which subsequently hydrolysed to $\mathrm{H}_{2} \mathrm{O}_{2}$. The first $\mathrm{H}_{2} \mathrm{O}_{2}$ plant using this process was implemented in 1908 in Weissenstein. Later, sulfuric acid was substituted by ammonium sulfate; the annual production of $\mathrm{H}_{2} \mathrm{O}_{2}$ using this process reached $35,000 \mathrm{t}$ in 1950 . $^{37}$

The electrochemical reduction of $\mathrm{O}_{2}$ was first reported as a means of producing $\mathrm{H}_{2} \mathrm{O}_{2}$ in the $1930 \mathrm{~s}$ by Berl;38 it used activated carbon as a cathode, achieving 90\% Faradaic efficiency. In the 1980s, Dow and Huron Technologies, Inc. adopted this method for the on-site production of dilute alkaline $\mathrm{H}_{2} \mathrm{O}_{2}$,Huron-Dow process (Figure 6a). Since dilute alkaline $\mathrm{H}_{2} \mathrm{O}_{2}$ is used for the pulp and paper bleaching process, ${ }^{,}$neither neutralization nor distillation is necessary, making the HuronDow process commercially viable. The Huron-Dow process was commercialized in 1991 and it is 
close to being competitive to the anthraquinone process. The major disadvantage of the HuronDow process is the high alkalinity of the working solution..$^{1439} \mathrm{H}_{2} \mathrm{O}_{2}$ readily decomposes in alkaline media, ${ }^{40}$ therefore it has to be used immediately. Additional disadvantages of this process include (i) the need to neutralize the solution for most applications, (ii) carbonate formation from $\mathrm{CO}_{2}$, (iii) the corrosion induced by the highly alkaline environment and (iv) the high Ohmic resistance, largely due to the ceramic membrane used to separate the anode and cathode.

The electro-Fenton process is a recent variant of the Huron-Dow process. In the Fenton method, a mixture of $\mathrm{H}_{2} \mathrm{O}_{2}$ and $\mathrm{Fe}^{2+}$ ions produce hydroxyl radicals $(\cdot \mathrm{OH})$; the hydroxyl radicals are then used to remove persistent organic pollutants. In the electro-Fenton process, $\mathrm{H}_{2} \mathrm{O}_{2}$ is produced insitu using electrochemistry, and $\mathrm{Fe}^{2+}$ is added to produce hydroxyl radicals (Figure 6b). A typical electro-Fenton process consists of two electrodes in an undivided cell with aqueous $\mathrm{Na}_{2} \mathrm{SO}_{4}$ electrolyte at $\mathrm{pH}$ 3. The optimal $\mathrm{pH}$ for the Fenton method is $\mathrm{pH} 3$; many research groups have focused on this particular $\mathrm{pH}$ for efficient removal of pollutants. The $\mathrm{H}_{2} \mathrm{O}_{2}$ concentrations produced by the electro-Fenton process range from $10 \mathrm{ppm}$ to $2 \%{ }^{2}$ The most frequently used cathode catalysts are carbon based materials such as graphite, ${ }_{, 1}^{41}$ carbon nanotubes ${ }_{, 2}^{42}$ carbon fiber ${ }_{, 3,44}^{4}$ carbon black ${ }^{45}$ and carbon sponge. ${ }^{46}$ Nitrogen ${ }^{47-50}$ or oxygen ${ }^{51}$ functional groups are sometimes introduced to carbon materials to improve catalytic properties. Polytetrafluoroethylene (PTFE, Teflon $®$ ) is often used with carbon materials as a binder, and to provide hydrophobicity. The electro-Fenton process is very effective, even with the most persistent organic pollutants. It has many advantages over the conventional Fenton process, where $\mathrm{H}_{2} \mathrm{O}_{2}$ and $\mathrm{Fe}^{2+}$ are added to the polluted water. In the electroFenton process, $\mathrm{H}_{2} \mathrm{O}_{2}$ is generated on-site and $\mathrm{Fe}^{2+}$ can be regenerated at the cathode (Figure 6b), therefore the required concentration of iron ions is an order of magnitude lower than the conventional Fenton method..$^{52}$ 
(a) Huron-Dow process

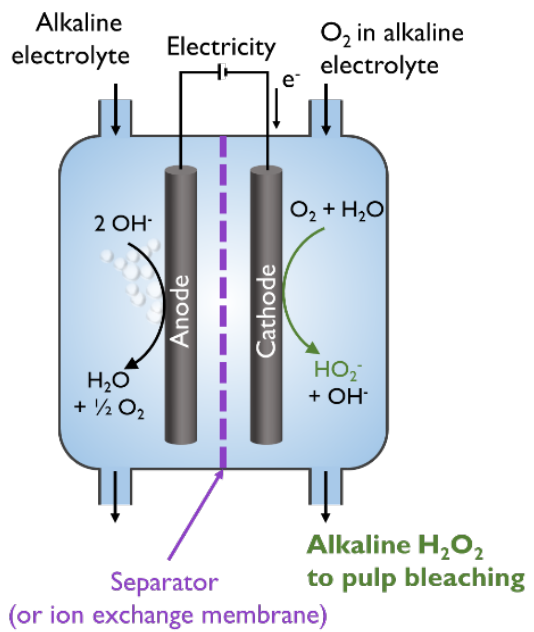

(c) Microbial electrosynthesis

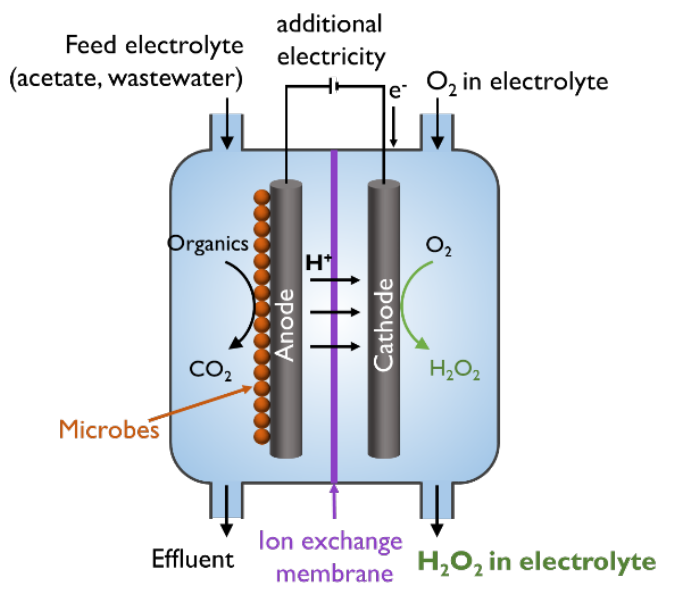

(b) Electro-Fenton process

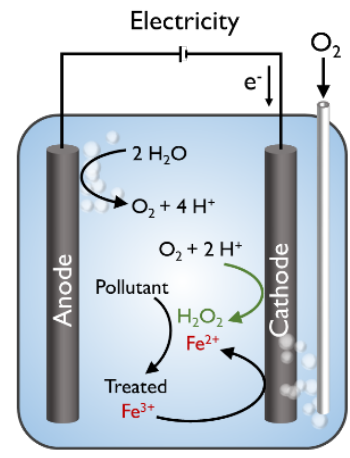

(d) $\mathrm{H}_{2} \mathrm{O}_{2}$ production using PEM electrolyser

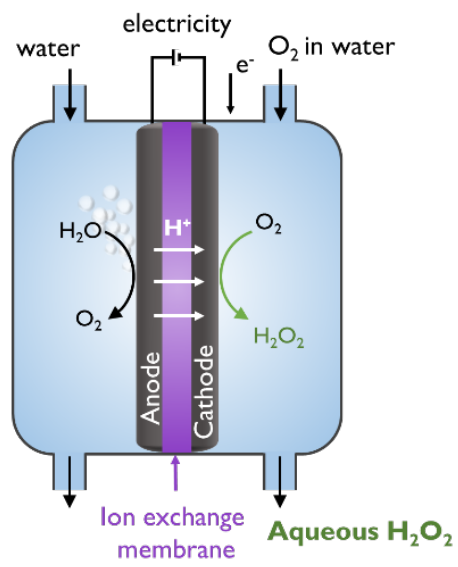

Figure 6. Schematic illustrations of different means of electrochemical $\mathrm{H}_{2} \mathrm{O}_{2}$ production.

(a) Huron-Dow process, cathodic $\mathrm{O}_{2}$ reduction in alkaline media. (b) Electro-Fenton process. (c) Microbial electrosynthesis. (d) Electrolytic $\mathrm{H}_{2} \mathrm{O}_{2}$ production using a PEM.

Microbial electrochemical cells can also produce $\mathrm{H}_{2} \mathrm{O}_{2}$ (Figure 6c)..$^{53}$ An aqueous solution containing acetate, or even wastewater, is used as a feed source to the anode. Microorganisms attached to the anode oxidise those organic solution phase species. In contrast to the electro-Fenton process, a cationic membrane separates anode and cathode electrolyte. Microbial electrochemical cells release electrical energy, hence function as fuel cells at the same time as producing $\mathrm{H}_{2} \mathrm{O}_{2}$. 
However, additional electrical energy is commonly added to enhance the rate of hydrogen peroxide production. Carbon-based materials such as carbon black, ${ }_{1,54}^{\text {sst }}$ graphite, ${ }^{5 s 56}$ carbon cloth $^{5 r}$ or a combination $^{s s}$ are used as cathode catalysts, similar to those used in the electro-Fenton process. Although these materials are highly selective, they exhibit a very low activity, meaning a large overpotential is required. Microbial electrochemical cells yield $\mathrm{H}_{2} \mathrm{O}_{2}$ concentrations ranging from $80 \mathrm{ppm}$ to $1 \%$. ${ }^{\text {s.5.s.s.s }}$ That way, $\mathrm{H}_{2} \mathrm{O}_{2}$ can be produced with energy scavenged from wastewater using microbial electrosynthesis.

As an aside, it is worth highlighting a recently investigated variant of electrochemical $\mathrm{H}_{2} \mathrm{O}_{2}$ production: through the anodic oxidation of water, albeit only consuming two electrons. ${ }^{\infty}$ Four electrons are required for the more ubiquitous variant of water oxidation: $\mathrm{O}_{2}$ evolution. In principle, it could enable the production of valuable chemical at the anode of electrolyser, rather than wasting energy by producing $\mathrm{O}_{2}$, (cf. Figure 6d). Shi et al. experimentally tested four oxide catalysts for anodic $\mathrm{H}_{2} \mathrm{O}_{2}$ production, chosen on the basis of DFT calculations. $\mathrm{BiVO}_{4}$ showed highest Faradaic efficiency of $70 \%$ without light illumination, and $98 \%$ with 1 sun illumination ${ }^{6}$, albeit at low current densities.

Yamanaka and co-workers pioneered the electrochemical production of $\mathrm{H}_{2} \mathrm{O}_{2}$ using proton exchange membrane (PEM) electrolytes. In their first work in this area, they set up a PEM fuel cell type configuration, where $\mathrm{H}_{2}$ was oxidized at the anode and $\mathrm{O}_{2}$ at the cathode..$^{2}$ The proton exchange membrane was based on Nafion, which has a highly acidic pH. They later adapted this design to an electrolyser setup, as shown in Figure 6d, where $\mathrm{O}_{2}$ evolution was used as a source of protons: this configuration negates the need to separately handle, produce (and possibly transport) $\mathrm{H}_{2}$. In a PEM configuration, the anode and cathode catalysts are in direct contact with the solid electrolyte. Both the cathode and anode are immersed in liquid water (Figure 6d). They tested 
several different cathode catalysts, including vapor-grown carbon fiber (VGCF), ${ }_{\text {,s }}$ activated carbon with VGCF, ${ }^{64}$ oxidized activated carbon with VGCF, ${ }^{6566} \mathrm{Co}-\mathrm{N}_{\mathrm{x}},{ }^{6,-70}$ and $\mathrm{Mn}-\mathrm{N}_{\mathrm{x}} \cdot{ }^{n} \mathrm{Using} \mathrm{Co}-\mathrm{N}_{\mathrm{x}} / \mathrm{C}$ as a cathode catalyst, Yamanaka and coworkers demonstrated that they could produce aqueous solutions of $\mathrm{H}_{2} \mathrm{O}_{2}$ at concentrations as high as $18.7 \mathrm{wt} \% \mathrm{H}_{2} \mathrm{O}_{2}$, with a Faradaic efficiency of $55 \% .{ }^{70}$

A key advantage of using the PEM configuration is that the $\mathrm{H}_{2} \mathrm{O}_{2}$ produced is $\mathrm{H}_{2} \mathrm{O}_{2}$ in pure water, as shown in Figure 6d. The product is thus ready to use; the other synthesis methods described above typically produce the $\mathrm{H}_{2} \mathrm{O}_{2}$ in media containing other compounds, necessitating additional purification steps. Winton et al. have shown that neutral $\mathrm{H}_{2} \mathrm{O}_{2}$ solution can be produced in a continuous-flow process adopting a PEM fuel cell configuration." Flow processes are less cumbersome than batch methods, reducing operating costs. As such, the PEM method is particularly suitable for small-scale, on-site, synthesis of dilute and neutral $\mathrm{H}_{2} \mathrm{O}_{2}$. Moreover, unlike the direct synthesis method, the potentially flammable mixture of $\mathrm{H}_{2}$ and $\mathrm{O}_{2}$ can be avoided. The technology also capitalizes upon ongoing advances in PEM electrolyser and fuel cell technology.

Much the same as for the direct synthesis process, the catalyst governs the efficiency of electrochemical $\mathrm{H}_{2} \mathrm{O}_{2}$ production. As such, a rapidly increasing body of research is being devoted to the catalysis of $\mathrm{O}_{2}$ reduction to $\mathrm{H}_{2} \mathrm{O}_{2}$. Below, we summarize our current understanding of this reaction. Moreover, going beyond the scope of other research papers, we review the challenges in implementing the catalysts into real devices.

3.1. Importance of catalysis in controlling $\mathrm{H}_{2} \mathrm{O}_{2}$ production. The performance of the catalyst strongly influences the overall cost of an electrochemical technology; as such, improvements in catalyst efficiency can be the main driver in major cost reductions. The total cost per mole of 
hydrogen peroxide $\left(C_{\text {total }}\right)$ can be expressed as the addition of two key parameters: electricity and capital cost: $C_{\text {total }}=C_{\text {electricity }}+C_{\text {capital }}$.

The total cost of electricity per mole $\mathrm{H}_{2} \mathrm{O}_{2}$ produced, $C_{\text {electricity }}=p_{\text {electricity }} U n F / \lambda_{\text {Faradaic }}$, where $p_{\text {ctatariay }}$ is the cost per unit energy of electricity $\left(\$ \mathrm{~J}^{-1}\right), U$ is the cell potential $(\mathrm{V}), n=2$, the number of electrons transferred per $\mathrm{H}_{2} \mathrm{O}_{2}$ molecule, $F$ is Faraday's constant $\left(96485.3 \mathrm{C} \mathrm{mol}^{-1}\right)$, and $\lambda_{\text {Faradaic }}$ is the Faradaic efficiency, defined as the ratio of charge converted to $\mathrm{H}_{2} \mathrm{O}_{2}$, to the total charge transferred. The capital costs per mole $\mathrm{H}_{2} \mathrm{O}_{2}$ produced, $C_{\text {capital }}=p_{\text {capital }} n F / j t \lambda_{\text {Faradaic }}$, where $p_{\text {capital }}$ is the capital cost per unit electrode area $\left(\$ \mathrm{~cm}^{2}\right), n=2$, the number of electrons transferred per $\mathrm{H}_{2} \mathrm{O}_{2}$ molecule, and $t$ is the total operating time of the plant over its lifetime (s), and $j$ is the current density $(\mathrm{A} \mathrm{cm})^{2}$. Neglecting operations and maintenance costs, the total costs, $C_{\text {total }}=\frac{p_{\text {electricity } U n F}}{\lambda_{\text {Faradaic }}}+\frac{p_{\text {capital }} n F}{j t \lambda_{\text {Faradaic }}}$. Since the denominator for both electricity costs and capital costs contain the term, $\lambda_{\text {Faradaic }}$, it is clear that the Faradaic efficiency plays a significant role in the economic efficacy of the process.

Costs related to electricity can be reduced by lowering $U$. The standard thermodynamic potential for electrolytic $\mathrm{H}_{2} \mathrm{O}_{2}$ production, $U_{0}^{\text {cell }}=U_{0}^{\mathrm{O}_{2} / \mathrm{H}_{2} \mathrm{O}}-U_{0}^{\mathrm{O}_{2} / \mathrm{H}_{2} \mathrm{O}_{2}}=0.53 \mathrm{~V}$ where the standard potential for $\mathrm{O}_{2}$ evolution $U_{0}^{\mathrm{O}_{2} / \mathrm{H}_{2} \mathrm{O}}=1.23 \mathrm{~V}$ and $\mathrm{H}_{2} \mathrm{O}_{2}$ production, $U_{0}^{\mathrm{O}_{2} / \mathrm{H}_{2} \mathrm{O}_{2}}=0.7 \mathrm{~V}$. However, overpotentials for both half-cell reactions result in $U$ being significantly larger than $0.53 \mathrm{~V}$. Notably, $j$ increases as a function of $U$. Consequently, there could be a pay-off in operating the electrolyser at high potential losses in order to maximize $j$; the exact extent of this payoff will depend on the ratio of $p_{\text {electricity }}$ to $p_{\text {capital }}$. Even so, the ideal cathode catalyst should be able to sustain high current densities without compromising on potential losses, or overpotentials. Importantly, costs related to capital can also be minimized by increasing the operating lifetime of 
the system, $t$, which highlights the relevance of catalyst stability. In the continuing section, we will discuss the design-criteria for efficient $\mathrm{H}_{2} \mathrm{O}_{2}$ production catalysis.

\section{TAILORING THE ELECTRODE; Fundamental aspects of the 2 electron process to} produce $\mathrm{H}_{2} \mathrm{O}_{2}$

4-1. Experimental state-of-the-art for electrochemical $\mathrm{H}_{2} \mathrm{O}_{2}$ production. As stated earlier, Yamanaka and co-workers produced $\mathrm{H}_{2} \mathrm{O}_{2}$ using PEM fuel-cell or PEM electrolyser-like devices (Figure 6d). The optimization of the cathode catalyst was one of their priorities. They first explored different metal catalysts and $\mathrm{Au}$ showed higher Faradaic efficiency than $\mathrm{Pd}, \mathrm{Pt}$, Ir, and $\mathrm{Rh}^{6.264}$ However, carbon materials were very efficient showing similar ${ }^{62}$ or even better ${ }^{64}$ Faradaic efficiency than Au. They also used graphitic carbon materials, vapor-grown carbon fibers (VGCF), ${ }^{63}$ activated carbon with VGCF, ${ }^{64}$ oxidized activated carbon with $\mathrm{VGCF}_{,}{ }^{6,566}$ and metal-nitrogen/carbon (M-N/C) catalysts, Co- $\mathrm{N}_{\mathrm{x}}{ }^{6-69}$ and $\mathrm{Mn}-\mathrm{N}_{\mathrm{x}} \cdot{ }^{11}$ Notably, several reports show that the oxidative treatment of carbon can yield higher rates of $\mathrm{H}_{2} \mathrm{O}_{2}$ production in a fuel cell configuration as well as in the electroFenton process. ${ }^{51,65}$ Incorporating phenol groups onto carbon electrodes improves the rates of $\mathrm{H}_{2} \mathrm{O}_{2}$ production in a PEM electrolyser setup..$^{66}$

Unlike Yamanaka et al, Sánchez-Sánchez and Bard quantified $\mathrm{H}_{2} \mathrm{O}_{2}$ production from oxygen reduction reaction (ORR) in $0.5 \mathrm{M} \mathrm{H}_{2} \mathrm{SO}_{4}$ using scanning electrochemical microscopy on different metal surfaces. ${ }^{{ }^{3}}$ The technique enabled fast screening of electrochemical ORR activity along with selectivity. $\mathrm{Hg}$ showed the highest selectivity, followed by $\mathrm{Au}, \mathrm{Ag}, \mathrm{Cu}$, and $\mathrm{AuCu}$. Conversely, $\mathrm{Pt}$, and PdCo followed the $4 \mathrm{e}-$ reduction pathway.

The rotating ring-disk electrode (RRDE) in a three electrode cell using liquid electrolytes is a simple, yet powerful, electrochemical method to quantitatively measure the production of $\mathrm{H}_{2} \mathrm{O}_{2}$ 


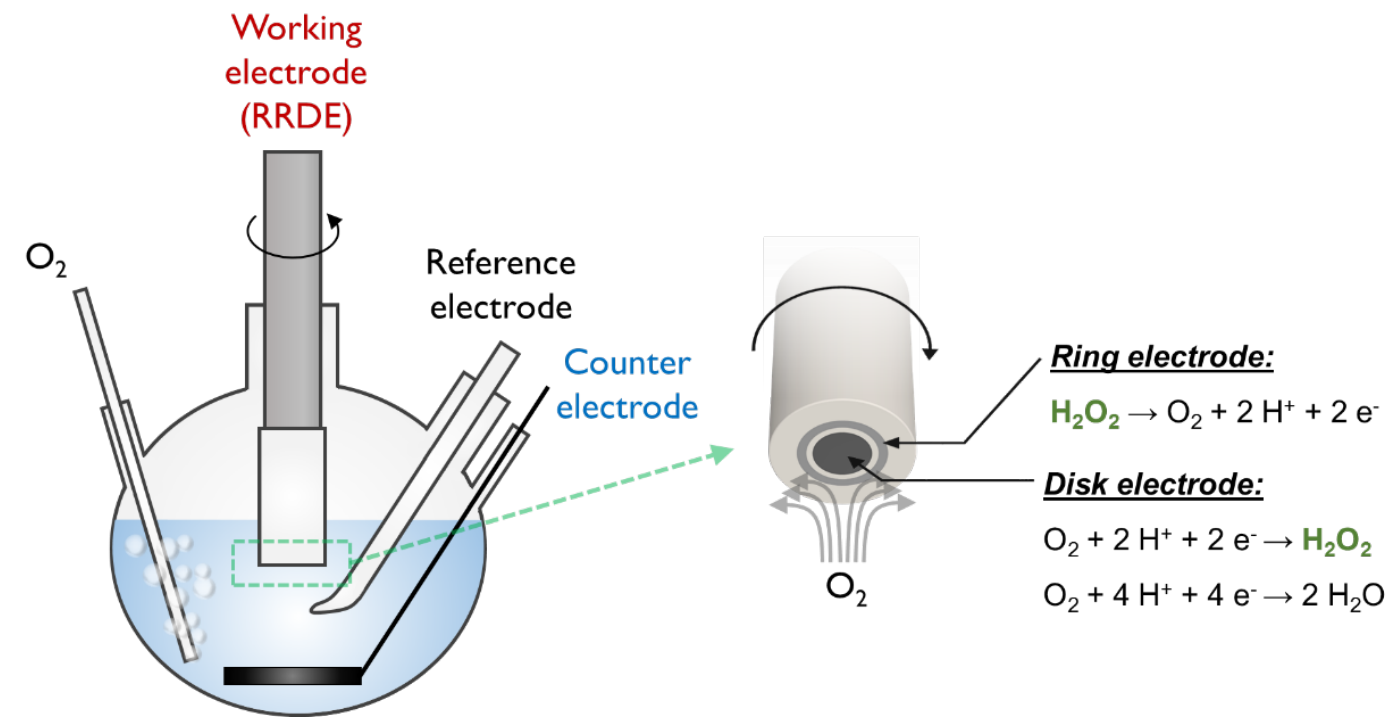

Figure 7. Schematic of a RRDE set-up in three-electrode electrochemical cell.

from oxygen reduction (Figure 7). In contrast to catalytic tests in real electrochemical devices, RRDE tests are simpler to optimize and yield high reproducibility on a laboratory-scale. ${ }^{745}$ Moreover, they are far more inexpensive than scanning electrochemical microscopes. Oxygen reduction takes place at the disk electrode; the catalyst can either be a bulk, planar extended surface or a thin film of supported nanoparticles ${ }^{74,55} \mathrm{H}_{2} \mathrm{O}_{2}$ produced at the disk electrode is radially transferred to the concentric platinum ring electrode by the forced convection caused by the rotating motion of the electrode. Subsequently, $\mathrm{H}_{2} \mathrm{O}_{2}$ is oxidized back to $\mathrm{O}_{2}$ at the ring electrode. We can calculate the selectivity the disk current and ring current by two means (i) the Faradaic efficiency, which we defined earlier:

$$
\text { Faradaic efficiency (\%) } \lambda_{\text {Faradaic }}=\frac{\frac{i_{R}}{N}}{i_{D}} \times 100
$$

, where $i_{\mathrm{R}}$ and $i_{\mathrm{D}}$ are ring and disk current respectively, and $N$ is collection efficiency of RRDE, or (ii) in terms of the fraction of $\mathrm{O}_{2}$ used for $\mathrm{H}_{2} \mathrm{O}_{2}{ }^{75}$

$$
\mathrm{O}_{2} \text { efficiency (\%) } \lambda_{\mathrm{O}_{2}}=\frac{2 \times \frac{i_{R}}{N}}{i_{D}+\frac{i_{R}}{N}} \times 100
$$


For the current paper, we have exclusively reported the selectivity in terms of Faradaic efficiency, as we take the view that it is the more relevant metric; this contrasts from our earlier works, where we provided the $\mathrm{O}_{2}$ efficiency. ${ }^{767}$

Numerous experimental groups have tested catalyst materials using the RRDE set-up. Figure 8a is a comparison of different electrocatalysts for $\mathrm{H}_{2} \mathrm{O}_{2}$ production, in the form of a Tafel plot. All measurements are conducted in aqueous solutions of $\mathrm{HClO}_{4}$ or $\mathrm{H}_{2} \mathrm{SO}_{4}$, with the exception of the glassy carbon (GC), which was conducted in alkaline solution, as we will discuss in Section 5-1. Figure $8 \mathrm{~b}$ shows the Faradaic efficiency of the same catalysts. These include (i) pure metal

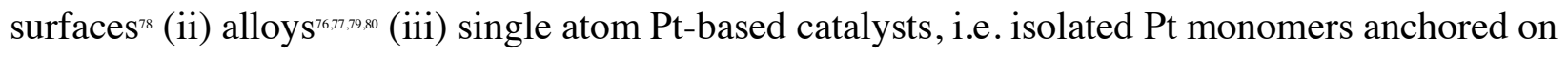
inert supports, ${ }^{s, 1,2}$ (iv) porphyrin and porphyrin like structures, Co-N/C $\mathrm{C}^{\cos s}$ and $\mathrm{Mn}-\mathrm{N} / \mathrm{C}^{n}$ (v) anthraquinone modified carbon, ${ }^{84}$ and (vi) N/C ${ }_{{ }^{s 5}}$ In terms of catalytic activity, $\mathrm{Pd}-\mathrm{Hg}$, which we discovered in an earlier study, is the superior catalyst in acid; it showed a Faradaic selectivity of $88 \%$, it was also highly stable in accelerated degradation tests." However, as shown in Figure 8b, several other catalysts show a peak Faradaic selectivity of $100 \%$, including $\mathrm{Au}(\mathrm{pc}), \mathrm{Ag}-\mathrm{Hg}(\mathrm{pc})$ and Co-N/C. The latter is of particular interest, because the activity is amongst the highest in Figure 8a. On the other hand, the stability of porphyrin and porphyrin-like structures tend to be low. ${ }^{86,87}$ High temperature annealing in inert atmosphere results in a significantly increased stability; however, the heat treatment tends to decrease the selectivity towards $\mathrm{H}_{2} \mathrm{O}_{2} .87,88$

4-2. Trends in oxygen electroreduction. The experimental determination of the oxygen reduction reaction mechanism is complicated by challenges in probing the reaction intermediates. As such, DFT-based models have been most fruitful in elucidating the reaction; ${ }^{8529}$ they show 

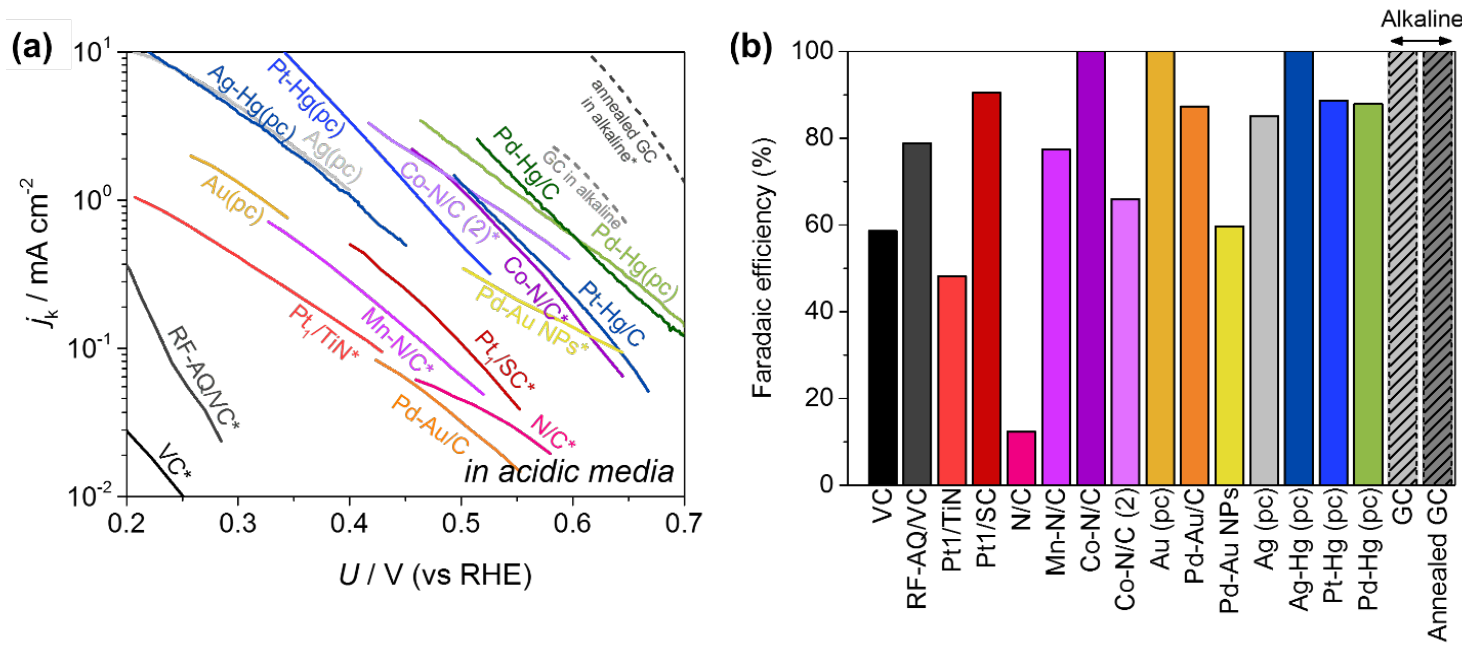

Figure 8. (a) Mass-transport corrected Tafel plots of kinetic current densities for $\mathrm{H}_{2} \mathrm{O}_{2}$ production in acidic media, based on rotating disk electrode or RRDE measurements. The kinetic currents correspond to the partial current densities for $\mathrm{H}_{2} \mathrm{O}_{2}$ production. Data are adapted from the literature as well as from our original data. (b) Corresponding Faradaic efficiency for each electrocatalyst. Data adapted from: $\operatorname{Ref}^{76}$ for $\mathrm{Pt}-\mathrm{Hg}(\mathrm{pc})$ and $\mathrm{Pt}-\mathrm{Hg} / \mathrm{C}$; Ref " for $\mathrm{Pd}-\mathrm{Hg}\left(\mathrm{pc}\right.$, polycrystalline) and $\mathrm{Pd}-\mathrm{Hg} / \mathrm{C}$; Ref ${ }^{p}$ for $\mathrm{Pd}-\mathrm{Au} / \mathrm{C}$; Ref ${ }^{78}$ for $\mathrm{Au}(\mathrm{pc})$; Ref ${ }^{80}$ for Pd-Au NPs; Ref 69 and Ref ${ }^{83}$ for Co-N/C and Co-N/C (2); Ref " for Mn-N/C; Ref ${ }^{s 1}$ for Pt1/TiN; Ref ${ }^{\text {s }}$ for Pt1/SC; ref ${ }^{\text {s }}$ for RF-AQ/VC, riboflavin-anthraquinone supported Vulcan XC72, and for VC, Vulcan XC72; Ref ${ }^{s 5}$ for N/C, N-doped carbon. Data noted with asterisk, *, have been normalized with geometric surface area of the working electrode. The dashed lines in are based on original data performed in alkaline media for glassy carbon (GC) electrode and annealed GC electrode (see Section 5-1).

particularly good agreement with experiments in acidic media. ${ }^{79394}$ Herein, we will make use of these models.2 The 2-electron pathway to $\mathrm{H}_{2} \mathrm{O}_{2}$ proceeds as follows:

$$
\mathrm{O}_{2}+*+\left(\mathrm{H}^{+}+\mathrm{e}^{-}\right) \rightarrow * \mathrm{OOH}
$$




$$
* \mathrm{OOH}+\left(\mathrm{H}^{+}+\mathrm{e}^{-}\right) \rightarrow \mathrm{H}_{2} \mathrm{O}_{2}
$$

where $*$ denotes an unoccupied active site or species adsorbed onto an active surface site. On the other hand, *OOH can undergo two different dissociation steps:

$$
\begin{aligned}
& * \mathrm{OOH}+\left(\mathrm{H}^{+}+\mathrm{e}^{-}\right) \rightarrow * \mathrm{O}+\mathrm{H}_{2} \mathrm{O} \\
& * \mathrm{OOH}+* \rightarrow * \mathrm{O}+* \mathrm{OH}
\end{aligned}
$$

which may lead to 4-electron (4e-) reduction to $\mathrm{H}_{2} \mathrm{O}$. The produced $\mathrm{H}_{2} \mathrm{O}_{2}$, from (8), may well be dissociated into two ${ }^{*} \mathrm{OH}$ or undergo further proton-electron transfer before it desorbs from the surface. Moreover, $\mathrm{H}_{2} \mathrm{O}_{2}$ in the bulk solution can re-adsorb on the active site and dissociate:

$$
\mathrm{H}_{2} \mathrm{O}_{2}+2 * \rightarrow * \mathrm{OH}+* \mathrm{OH}
$$

or electrochemically be reduced further:

$$
\mathrm{H}_{2} \mathrm{O}_{2}+\left(\mathrm{H}^{+}+\mathrm{e}^{-}\right)+* \rightarrow * \mathrm{OH}+\mathrm{H}_{2} \mathrm{O}
$$

The dissociation intermediates, $* \mathrm{OH}$ and $* \mathrm{O}$, can be further reduced, closing the reduction process by producing $\mathrm{H}_{2} \mathrm{O}$ via 4-electron reduction:

$$
\begin{aligned}
* \mathrm{O} & +\left(\mathrm{H}^{+}+\mathrm{e}^{-}\right) \rightarrow * \mathrm{OH} \\
& * \mathrm{OH}+\left(\mathrm{H}^{+}+\mathrm{e}^{-}\right) \rightarrow \mathrm{H}_{2} \mathrm{O}+*
\end{aligned}
$$

Similar to the direct synthesis method, the question of whether $\mathrm{H}_{2} \mathrm{O}$ or $\mathrm{H}_{2} \mathrm{O}_{2}$ is produced depends on the ability of the catalyst to dissociate the oxygen-oxygen bond.

Electronic effects completely control the catalytic activity and partially control the catalytic selectivity. We discussed such effects earlier in this article for the case of the direct synthesis method (Figure 4b).$^{28}$ However, in contrast to the direct synthesis method, the catalyst from which 
$\mathrm{H}_{2} \mathrm{O}_{2}$ is produced does not need to dissociate $\mathrm{H}_{2}$; protons would be produced separately at the cathode. This simplifies the Sabatier volcano analysis: only the binding energy of one Ocontaining intermediate is needed to describe the overall trends. Figure 9a is the Sabatier volcano for oxygen reduction for metal surfaces and metal-nitrogen/carbon (M-N/C, inset of Figure 10) structures. The green lines in Figure 9a derive from the thermodynamic equilibrium for the different limiting steps in the 2 electrons reduction to $\mathrm{H}_{2} \mathrm{O}_{2}$. For a given $* \mathrm{OOH}$ adsorption energy, they allow extrapolation of the theoretical minimum overpotential required by each catalyst. The step of $\mathrm{O}_{2}$ reduction to $* \mathrm{OOH}$ limits the reaction at the weak binding, right-hand leg of the volcano. Conversely, ${ }^{*} \mathrm{OOH}$ reduction to $\mathrm{H}_{2} \mathrm{O}_{2}$ limits the strong binding, left-hand leg. The most active catalyst for $\mathrm{H}_{2} \mathrm{O}_{2}$ production would sit at the peak of the 2-electron volcano. The black lines represent the limiting potentials for the 4-electron volcano for $\mathrm{H}_{2} \mathrm{O}$ production. To the left of the peak of the 2-electron volcano, the limiting potentials of the 4-electron route are always more positive, i.e. there is a greater driving force for $\mathrm{H}_{2} \mathrm{O}$ production than $\mathrm{H}_{2} \mathrm{O}_{2}$ production for strong binding catalysts. To the right of the peak of the 2-electron volcano, the limiting potential for both pathways overlap. Amongst the pure metal surfaces, only Au sits on the weak binding leg; amongst the M-N/C structures, Cu-N/C, Ni-N/C, Pd-N/C, Pt-N/C also lie on the weak binding leg. We also report in Figure 9a the data points for $\mathrm{Hg}$ and graphene surfaces. Hg atoms were immobilized in a face-centred cubic (FCC) structure, although under real reaction conditions we acknowledge it is in liquid phase.

According to Figure 9a, no metal surface or M-N/C structure has the optimal electronic structure to exhibit highest possible activity for $\mathrm{H}_{2} \mathrm{O}_{2}$ production in Figure 9a. Guided by a theoretical screening study, we discovered that we could tune the $* \mathrm{OOH}$ binding of Pt and Pd towards optimal values by alloying with $\mathrm{Hg}$, resulting in a high activity for $\mathrm{H}_{2} \mathrm{O}_{2}$ production. ${ }^{6677}$ The outcome is 

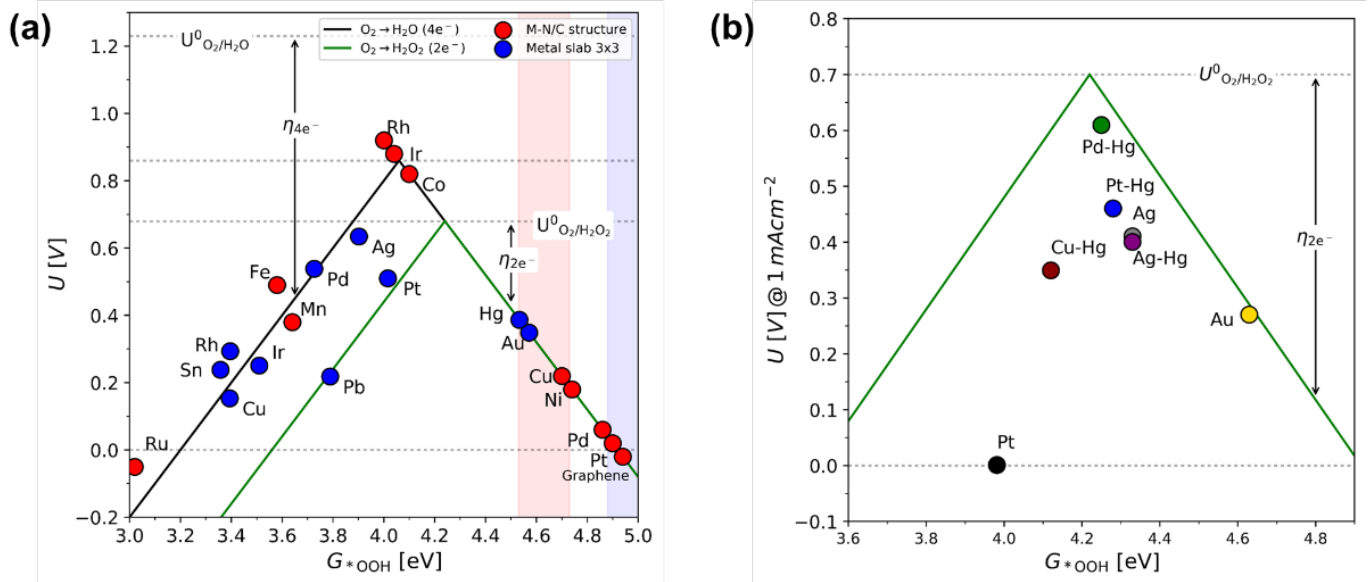

Figure 9. (a) Sabatier volcano plots for electrochemical oxygen reduction for closely packed pure metal slabs (in blue) and M-N/C structures (in red), obtained from DFT calculations. The limiting potential is plotted as a function of $\Delta G_{\text {оон }}$ The green line represents 2-electron reduction, and the black line represents 4 -electron reduction. The volcanoes are based on an earlier model $;^{92}$ the individual data points represent original data produced for the current publication. M-N/C catalysts lying to the right of the horizontal red band bind $* O$ sufficiently weak to thermodynamically favor the 2 electron pathway to $\mathrm{H}_{2} \mathrm{O}_{2}$; pure metal catalysts lying to the right of the horizontal blue band bind *O sufficiently weak to thermodynamically favor the 2 electron pathway to $\mathrm{H}_{2} \mathrm{O}_{2}$. These boundaries are shown as bands, rather than lines to represent the inherent uncertainty in the model. (b) Experiment versus theory for pure metals and metal alloys, adapted from Ref ${ }^{n}$. The solid line shows the limiting potential from DFT, also shown in $a$. Circles represents potential required to reach kinetic current of $1 \mathrm{~mA} / \mathrm{cm}^{2}$ on polycrystalline electrodes.

represented on Figure $9 b$, where we plot the experimental potential req uired to drive $1 \mathrm{~mA} / \mathrm{cm}^{2}$ as a function of the theoretical $* \mathrm{OOH}$ binding energy for both $\mathrm{Hg}$-based alloys and pure metals. The experiments agree well with the Sabatier volcano: $\mathrm{Pd}-\mathrm{Hg}$, the most active catalyst, lies at the peak. 
However, the origin of the high selectivity of $\mathrm{Hg}$-alloys and some of the other catalysts described above is not purely due to electronic effects; geometric effects also play a role. Interestingly, these seem to play a much stronger role in determining selectivity for the electrochemical process than in the direct synthesis method (see section 2). Regardless of whether $\mathrm{O}_{2}$ reduction proceeds via the chemical or the electrochemical dissociation of $* \mathrm{OOH}, * \mathrm{O}$ will constitute one of the dissociation products on the way to $\mathrm{H}_{2} \mathrm{O}$, equation (9) and (10). Thus. the destabilization of the $* \mathrm{O}$ intermediate with respect to $\mathrm{H}_{2} \mathrm{O}_{2}$ (the free energy of which is constant at $3.56 \mathrm{eV}$, relative to $\mathrm{H}_{2} \mathrm{O}$ ) should increase selectivity. The preferred adsorption sites of $* \mathrm{O}$ are the hollow or bridge site on metal surfaces, whereas the preferred adsorption site of $* \mathrm{OOH}$ is the atop site.$^{76}$ Consequently, adsorption on a single site would constrain the adsorption to the atop site, destabilizing all intermediates, albeit in different ways. While destabilization of $* \mathrm{OOH}$ results in activity loss, a weaker $* \mathrm{O}$ binding energy results in a significantly improved selectivity. We clarify such a phenomenon using the DFT-based plot on Figure 10: it shows that the free energy of $* \mathrm{O}$ adsorption, $\Delta G_{* 0}$, as a function of the free energy of adsorption of $* \mathrm{OOH}, \Delta G_{* \mathrm{OOH}}$, for a number of different surfaces. Porphyrin type catalysts (M-N/C) are shown in red, while face-centred cubic (FCC) metal (111) terraces are shown in blue. We have fitted the trend for each of the two classes of material; *O adsorption is $\sim 0.7 \mathrm{eV}$ weaker on a M-N/C structure, in comparison to a FCC (111) surface with the same $* \mathrm{OOH}$ adsorption energy. The horizontal dashed line demarcates $\Delta G_{\mathrm{H}_{2} \mathrm{O}_{2}}$, the free energy of $\mathrm{H}_{2} \mathrm{O}_{2}$, relative to $\mathrm{H}_{2} \mathrm{O}$. In order for a catalyst to thermodynamically favor $\mathrm{H}_{2} \mathrm{O}_{2}$ production, relative to $\mathrm{H}_{2} \mathrm{O}$, the $* \mathrm{O}$ formation (c.f. equation 9) should be greater than $\Delta G_{\mathrm{H}_{2} \mathrm{O}_{2}}$. Only the catalysts lying above the dashed line on Figure 10, such as $\mathrm{Cu}-\mathrm{N} / \mathrm{C}, \mathrm{Ni}-\mathrm{N} / \mathrm{C}, \mathrm{Pd}-\mathrm{N} / \mathrm{C}$ and $\mathrm{Pt}-\mathrm{N} / \mathrm{C}$, present a greater thermodynamic drive to $\mathrm{H}_{2} \mathrm{O}_{2}$ desorption rather than *O formation . On M-N/C catalysts, the lack of contiguous metal sites would prevent the chemical dissociative mechanism 


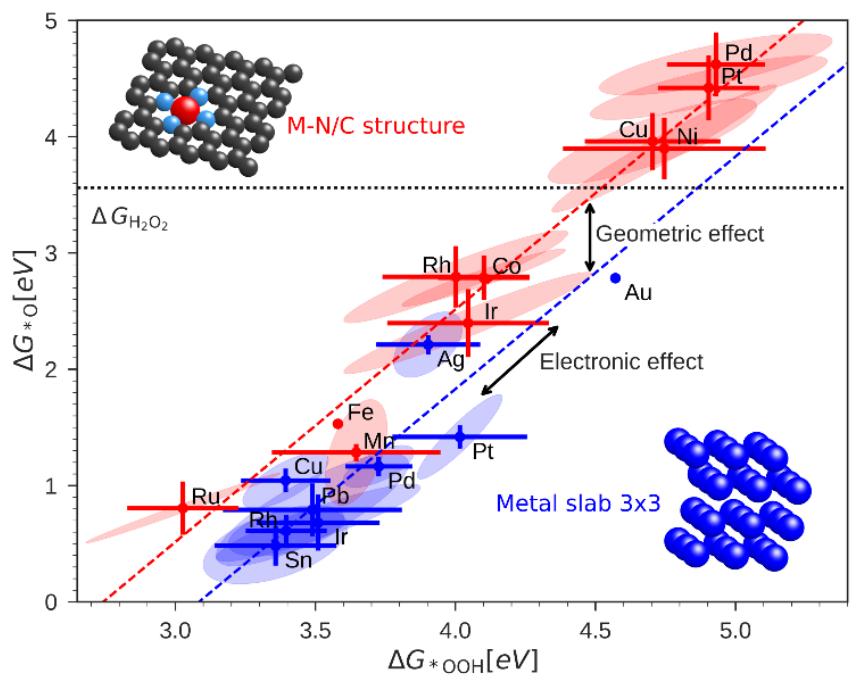

Figure 10. Adsorption trend for selected metal slabs and M-N/C catalysts. Original data.

described by equation (10), limiting the possible routes to $\mathrm{H}_{2} \mathrm{O}$. Similarly, on M-N/Cs the decomposition of $\mathrm{H}_{2} \mathrm{O}_{2}$ is inhibited; the dissociative chemical re-adsorption in equation (11) cannot happen without two neighbor adsorption sites. On metal slabs instead, active sites are closely packed and the chemical dissociations in equations (10) and (11) are feasible..5 Notably, equation 12 does not involve the formation of *O; the selectivity is directed by the affinity towards $* \mathrm{H}_{2} \mathrm{O}_{2}$ adsorbate and could be significant at high pero xide concentrations. The dashed line in Figure 10,

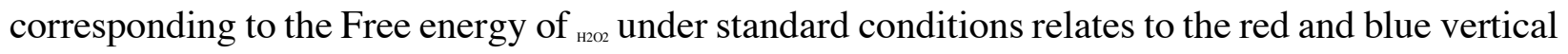
bands on Figure 9a: M-N/C structures lying to the right of the vertical red band favor the 2-electron pathway over the 4-electron pathway; closely packed metal surfaces to the right of the blue band favor the 2-electron pathway over the 4-electron pathway. Curiously, this theoretical thermodynamic analysis would suggest that several catalysts, such as $\mathrm{Co}-\mathrm{N} / \mathrm{C}$ or $\mathrm{Au}$, should not be selective to $\mathrm{H}_{2} \mathrm{O}_{2}$ production. However, as shown in Figure 8, RRDE experiments show that in $0.1 \mathrm{M} \mathrm{HClO}_{4}$, these catalysts are indeed highly selective to $\mathrm{H}_{2} \mathrm{O}_{2}$ production. ${ }^{6978,8,83}$ This discrepancy could suggest that additional kinetic barriers exist in acid electrolyte, that serve to preserve the O- 
$\mathrm{O}$ bond and favor $\mathrm{H}_{2} \mathrm{O}_{2}$ production. Moreover, we note that the free energy of $\mathrm{H}_{2} \mathrm{O}_{2}$ on Figure 10 is under standard conditions; at lower concentrations the vertical red and blue lines on Figure 9a would shift to the left. To the contrary, more accurately defined solvation effects may shift the red line to the right. ${ }^{\circ}$ Nonetheless, our new DFT simulations describe a key thermodynamic trend: catalysts that exhibit weak binding to ${ }^{*} \mathrm{O}$, relative to the $\mathrm{H}_{2} \mathrm{O}_{2}$ energy level, should favor $\mathrm{H}_{2} \mathrm{O}_{2}$ production.

Collman, Anson and coworkers provided an elegant experimental demonstration of geometric versus electronic effects, albeit in three dimensions, almost four decades ago. ${ }^{p}$ Figure 11 shows RRDE measurements of a monomeric cobalt porphyrin in comparison to a di-cobalt face-to-face porphyrin. Cobalt porphyrins consist of an active Co atom surrounded by less reactive $\mathrm{N}$ atoms, i.e. a prototypical isolated active site (inset of Figure 11a). However, in the di-cobalt face-to-face porphyrin, two porphyrin layers are adjacent to each other (inset of Figure 11b) with a $4 \AA$ distance. The regular porphyrin structure is selective for $\mathrm{H}_{2} \mathrm{O}_{2}$ production, with high currents at the ring of the RRDE. The di-cobalt structure has high currents at the disk and much lower currents at the ring, revealing lower selectivity to $\mathrm{H}_{2} \mathrm{O}_{2}$ and a high activity for $\mathrm{H}_{2} \mathrm{O}$ production. We anticipate that the binding to ${ }^{*} \mathrm{OOH}$ is the same in the Co of both structures; hence we can neglect electronic effects. We attribute the high selectivity of the monomeric porphyrin to the presence of an isolated active site. However, in the di-cobalt face-to-face porphyrin the $\mathrm{O}_{2}$ molecule would adsorb between 
(a)

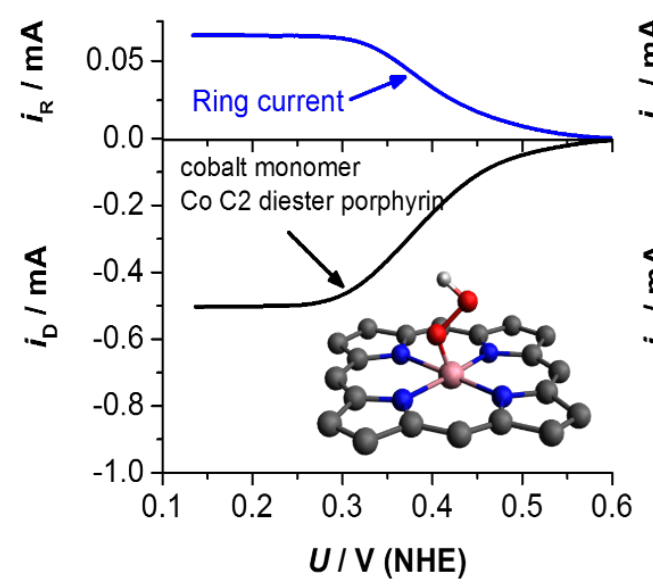

(b)

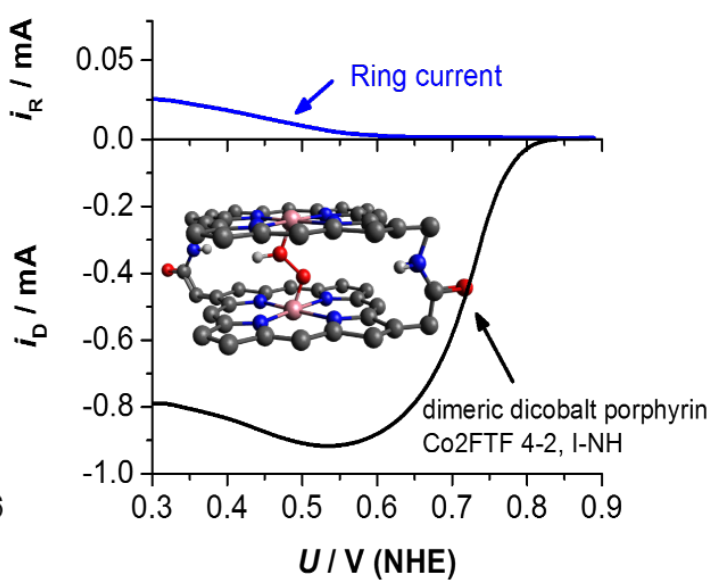

Figure 11. Rotating ring disk electrode (RRDE) measurements of (a) monomeric cobalt porphyrin and (b) di-cobalt face-to-face porphyrin in $\mathrm{O}_{2}$ saturated $0.5 \mathrm{M} \mathrm{CF}_{3} \mathrm{CO}_{2} \mathrm{H}$ at a rotating rate of $250 \mathrm{rpm}$. Insets are schematic of oxygen molecule interacting with cobalt porphyrin molecule. Carbon, grey; nitrogen, blue; cobalt, pink; oxygen, red; hydrogen; white. Adapted from Ref ${ }^{\natural}$.

the two adjacent Co atoms, as shown in the sc hematic figure, allowing it to be dissociated. Hence the difference between the two structures is due to geometric effects.

In addition to the above example, there are numerous reports of Co-N/C type structures being used for $\mathrm{H}_{2} \mathrm{O}_{2}$ production (also compare with Figure 9). ${ }^{6-69988}$ Many research groups have investigated metal porphyrin type catalysts to replace Pt catalysts in fuel cell cathodes for the $4 \mathrm{e}$ - pathway. Fe$\mathrm{N} / \mathrm{C}$ catalysts are the most well-known catalysts for this purpose. ${ }^{90103}$ In M-N/C catalysts, the composition of the reactive metal atom, ${ }^{10-106}$ the ligand structure, ${ }^{8,10-10100}$ the redox potential of the metal ligand couple, ${ }^{104}$ the loading, ${ }^{10.11}$ the carbon support, and the thermal treatment ${ }^{\text {ss.os }}$ can contribute to changes in activity and selectivity for the ORR. . $^{\text {s.112 }}$

There are many other strategies to realize isolated active sites. One such example is by alloying active atoms with inert atoms. For instance, alloying metals such as Pt and Pd with $\mathrm{Hg}$ not only 
tune the $* \mathrm{OOH}$ binding of noble metals (as discussed above), but also leads to the formation of a self-organized surface structure to form isolated active atoms of Pt, surrounded by inert atoms, Hg. ${ }^{113}$ Adopting this strategy, we showed that both $\mathrm{PtHg},{ }^{76}$ and $\mathrm{PdHg},{ }^{77}$ exhibited a high selectivity. This phenomenon is also the origin of the high selectivity of AuPd ${ }^{79 s 0}$ electrocatalyst alloys. Another means of producing isolated sites is to cover Pt nanoparticles with an inert material, such as amorphous carbon. ${ }^{114}$ Single-atom catalysts, e.g. isolated active atoms anchored on supports, also benefit from geometric effects. Single-atom catalysts of $\mathrm{Pt}$ on titanium nitride (TiN), ${ }^{81}$ titanium carbide (TiC), ${ }^{115}$ and sulphur doped carbon"s have shown high selectivity toward $\mathrm{H}_{2} \mathrm{O}_{2}$.

Aside from the above electrodes, which consist of at least one metallic element, carbon electrodes are also selective for $\mathrm{H}_{2} \mathrm{O}_{2}$ production, albeit with very low activity, which we attribute to the inherently weak interaction between $\mathrm{C}$ and $* \mathrm{OOH}$; as demonstrated by the graphene point at $5.24 \mathrm{eV} * \mathrm{OOH}$ binding energy in Figure 9a, this material binds the intermediates weaker than any of the other materials calculated. Additional treatments can increase the activity of carbon catalysts, such as the introduction of anthraquinone molecules, in analogy to the anthraquinone process $^{84,16-119}$ Another route is to functionalize carbon with nitrogen ${ }^{47-50}$ or oxygen ${ }^{51.6566}$ functional groups. Compensating for its low intrinsic activity, carbon is inexpensive and can be easily

produced in a high surface area form. For this reason, carbon materials have been widely used in the synthesis of $\mathrm{H}_{2} \mathrm{O}_{2}$ in electro-Fenton process and in microbial electrochemical cells (see section 3).

\section{TAILORING THE ELECTROLYTE; pH effect}

5-1. pH effect on activity and selectivity for $\mathrm{H}_{2} \mathrm{O}_{2}$. With the advent of hydroxide conducting polymeric membranes, ${ }^{120}$ there is increased interest in catalyzing $\mathrm{O}_{2}$ reduction to $\mathrm{H}_{2} \mathrm{O}_{2}$ and $\mathrm{H}_{2} \mathrm{O}$ in alkaline-as opposed to acidic-media. ${ }^{121,122}$ In Section 4, we established that in acid, the overall 
trends in $\mathrm{O}_{2}$ reduction are well described by DFT-based models, which focus on the thermodynamics of each coupled proton electron transfer. Should we consider the adsorption of the oxygen reduction intermediates, ${ }^{*} \mathrm{OH},{ }^{*} \mathrm{OOH}$ and $* \mathrm{O}$, to be controlled by the equilibrium between $\mathrm{O}_{2}, \mathrm{H}_{2} \mathrm{O}$, protons and electrons, then the overall thermochemistry of oxygen reduction should be largely $\mathrm{pH}$-independent on the RHE scale. ${ }^{123,124}$ However, experiments suggest that in base, some key trends differ significantly from acid. ${ }^{25}$ Pt-based surfaces typically follow the 4-electron route to water, except at very negative potentials where the surface is covered with $* \mathrm{H} .{ }^{126}$ As we showed in a very recent paper, around the peak of the four electron volcano, the binding to reaction intermediates controls the activity in alkaline media in a similar means to acid: low index facets of $\mathrm{Pt}, \mathrm{Pt}$ alloys and $\mathrm{Au}(100)$ are well described by the Sabatier volcano model. ${ }^{127}$ However, stepped surfaces and nanoparticulate Pt seems to be less active in alkaline media than low index facets, ${ }^{128,129}$ despite exhibiting the optimal binding to $\mathrm{OH}$. The oxygen reduction activity of Pt-based surfaces is roughly $\mathrm{pH}$ independent on the RHE scale, varying by up to an order of magnitude between $\mathrm{pH}$ 1 and $\mathrm{pH} 13 .{ }^{126,130}$ The activity of Pt also changes somewhat as a function of electrolyte cation, even at constant $\mathrm{pH} .^{.27,131}$ Conversely, Ag-based surfaces shows a much stronger $\mathrm{pH}$ dependence than Pt: for instance, $\mathrm{Ag}(111)$ it is quite selective and active for the 2-electron route to $\mathrm{H}_{2} \mathrm{O}_{2}$ in acidic media. ${ }^{77}$ In alkaline media, it shows high oxygen reduction activity for the 4-electron pathway; for that reason, Ag has been used in alkaline fuel cells. ${ }^{132,133} \mathrm{Au}$ is similar to $\mathrm{Ag}$ : in acidic media most Au-based catalysts are selective to the 2-electron pathway and fairly inactive..$^{78}$ In alkaline media, Au surfaces are generally more active and selective to the 4-electron route; the (100) facet is particularly active..$^{134,135}$

Carbon-based catalysts show an even more pronounced $\mathrm{pH}$ dependence than $\mathrm{Au}$ or Ag. Jaramillo and coworkers demonstrated that in $0.1 \mathrm{M} \mathrm{KOH}$, glassy carbon shows exceptionally high activity 

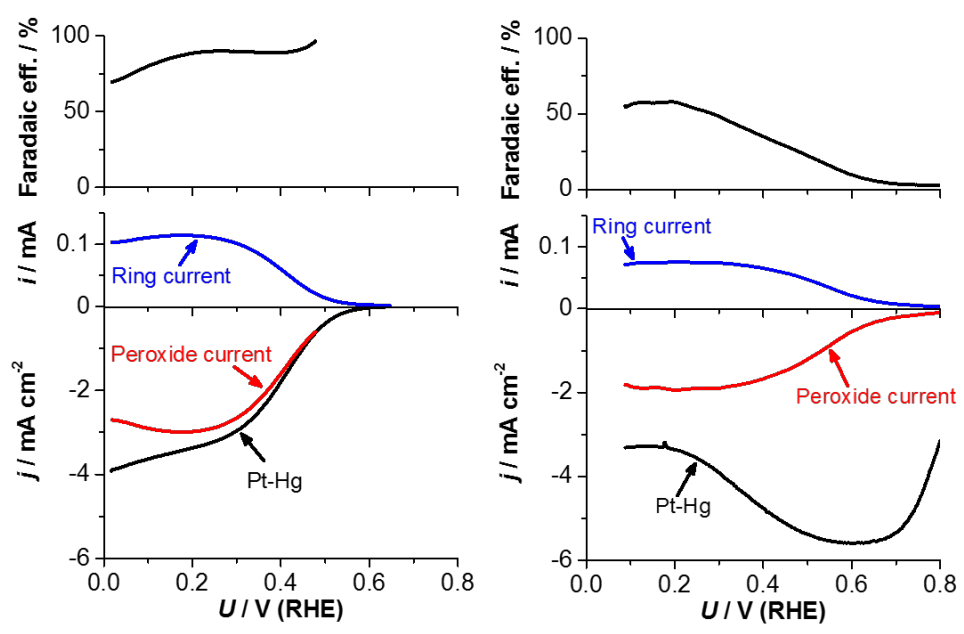

Figure 12. Oxygen reduction on $\mathrm{Pt}-\mathrm{Hg}(\mathrm{pc})$ using a rotating ring-disk electrode. a) Measurement in $0.1 \mathrm{M} \mathrm{HClO}_{4}$ b) Measurement in $0.1 \mathrm{M} \mathrm{KOH}$. All data taken at $50 \mathrm{mV} / \mathrm{s}$ and $1600 \mathrm{rpm}$ at room temperature. Data for (a) is previously reported in $\operatorname{Ref}^{76}$, and (b) is original data

for $\mathrm{H}_{2} \mathrm{O}_{2}$ production - in particular when it is annealed in air. ${ }^{136}$ Conversely, in acid, glassy carbon is so inactive $e^{75,137-139}$ that it would not even lie on the Tafel plot on Figure 8a; it only shows a measureable current below 0.2 V RHE. Indeed, the improved selectivity and activity of carbon at high $\mathrm{pH}$ motivated Gyenge et al to add cationic surfactants to the electrolyte..$^{140,41}$ In summary, it seems that the most weak-binding surfaces (see Figure 9a) show the strongest pH dependence.

In this Section, we aim to establish the differences in activity and selectivity between acid and base for oxygen reduction to $\mathrm{H}_{2} \mathrm{O}_{2}$. We have tested several different extended surfaces, including $\mathrm{Pt}(\mathrm{pc}), \mathrm{Pt}-\mathrm{Hg}, \mathrm{Ag}(\mathrm{pc}), \mathrm{Ag}-\mathrm{Hg}$ and glass y carbon, using RRDE measurements in $0.1 \mathrm{M} \mathrm{HClO}_{4}$ and $0.1 \mathrm{M} \mathrm{KOH}$ measurements. Several, but not all of these surfaces, are reported elsewhere..$^{12-146}$ 
(a) $\mathrm{Ag}(\mathrm{pc})$ in $0.1 \mathrm{M} \mathrm{HClO}$
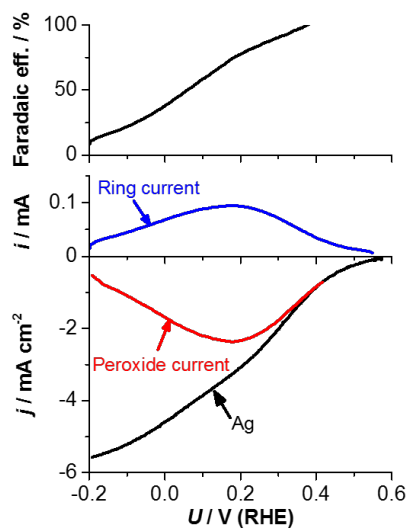

(c) $\mathrm{Ag}-\mathrm{Hg}(\mathrm{pc})$ in $0.1 \mathrm{M} \mathrm{HClO}_{4}$

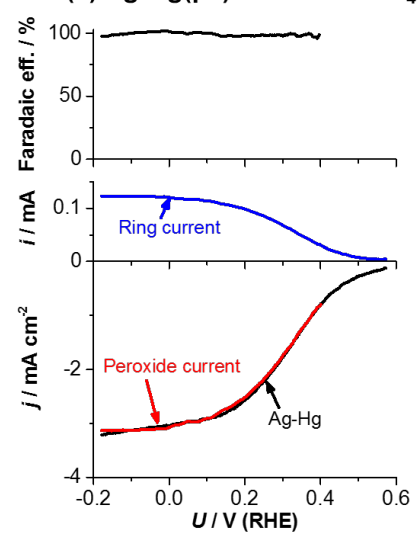

(b) $\mathrm{Ag}(\mathrm{pc})$ in $0.1 \mathrm{M} \mathrm{KOH}$
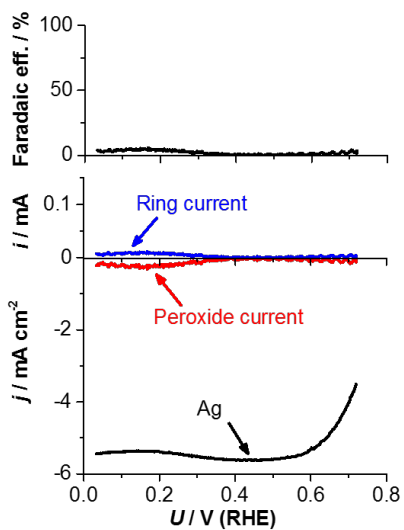

(d) $\mathrm{Ag}-\mathrm{Hg}(\mathrm{pc})$ in $0.1 \mathrm{M} \mathrm{KOH}$

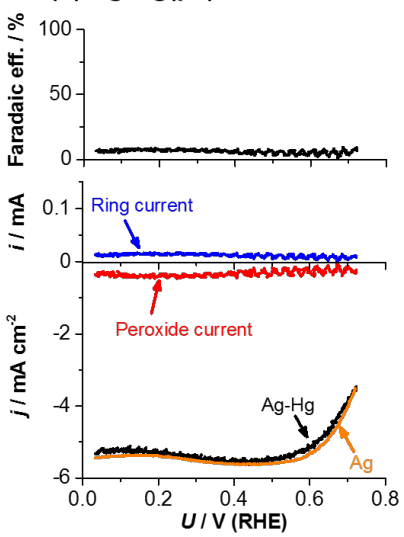

Figure 13. Oxygen reduction on (a), (b) $\mathrm{Ag}$ and (c), (d) $\mathrm{Ag}-\mathrm{Hg}$ using a rotating ring-disk electrode. (a), (c) Measurement in $0.1 \mathrm{M} \mathrm{HClO}_{4}$. (b), (d) Measurement in 0.1 M KOH. All data taken at $50 \mathrm{mV} / \mathrm{s}$ and $1600 \mathrm{rpm}$ at room temperature. Original data

However, by testing all the surfaces in a single study, we aim to provide benchmark performance data. On this basis, we discuss possible reasons for the phenomena we observe.

On Figure $12 \mathrm{a}$ we present $\mathrm{O}_{2}$ reduction on polycrystalline $\mathrm{Pt}-\mathrm{Hg}$ in $0.1 \mathrm{M} \mathrm{HClO}_{4}$, which we reported previously ${ }_{,}^{76}$ while in Figure $12 \mathrm{~b}$ we show new data in $0.1 \mathrm{M} \mathrm{KOH}$. In $0.1 \mathrm{M} \mathrm{HClO}_{4}$, we achieved up to $85 \%$ Faradaic efficiency and high activity. In contrast, in $0.1 \mathrm{M} \mathrm{KOH}$, the catalyst shows much lower selectivity and lower peroxide current densities; however, it is fairly active to the 4electron route, reaching the transport limiting current at around $0.7 \mathrm{~V}$. 
On Figure 13a and $b$ we present data for polycrystalline Ag. We observe a Faradaic efficiency to $\mathrm{H}_{2} \mathrm{O}_{2}$ as high as $100 \%$ in $0.1 \mathrm{M} \mathrm{HClO}_{4}$, which decreases with increasing overpotential. Conversely, in $0.1 \mathrm{M} \mathrm{KOH}$, the catalyst is almost completely selective to $\mathrm{H}_{2} \mathrm{O}$ production. Marković and co-workers reported qualitatively sim ilar data for $\operatorname{Ag}(111)$, albeit with lower selectivity to $\mathrm{H}_{2} \mathrm{O}_{2}$ in $0.1 \mathrm{M} \mathrm{HClO}_{4}$. $\mathrm{Ag}-\mathrm{Hg}$, shown on Figure 13 (c) and (d), shows remarkably similar behavior to $\mathrm{Ag}$. In $0.1 \mathrm{M} \mathrm{HClO}_{4}$ it shows $100 \%$ Faradaic efficiency to $\mathrm{H}_{2} \mathrm{O}_{2}$ across the entire potential range, albeit with very similar activity to $\mathrm{Ag}$; in $0.1 \mathrm{M} \mathrm{KOH}$, it is highly active and completely selective towards the 4-electron route to water. In our earlier study, we attributed the activity of $\mathrm{Ag}$ and $\mathrm{Ag}-\mathrm{Hg}$ towards $\mathrm{H}_{2} \mathrm{O}_{2}$ production in $0.1 \mathrm{M} \mathrm{HClO}_{4}$ to the terraces. ${ }^{n}$ We proposed that on $\mathrm{Ag}-\mathrm{Hg}$, all the $\mathrm{Hg}$ resided on undercoordinated sites, which would be the active sites for $\mathrm{H}_{2} \mathrm{O}_{2}$ reduction to $\mathrm{H}_{2} \mathrm{O}$, explaining the improved activity. Presumably, in base, the terraces are also active for $\mathrm{H}_{2} \mathrm{O}$ production.

In Figure 14a, the glassy carbon (GC) electrode in acidic electrolyte showed very poor activity, though its Faradaic efficiency was above $85 \%$. In alkaline solution, Figure 14b, the GC electrode is not only active but also highly selective, showing above $90 \%$ Faradaic efficiency, over the entire potential range studied. The high activity and selectivity of carbon makes it a suitable catalyst for alkaline $\mathrm{H}_{2} \mathrm{O}_{2}$ production (Figure 6a). Inspired by earlier precedents, ${ }^{136}$ we also tested the effect of annealing the electrode in air at $500{ }^{\circ} \mathrm{C}$ for $10 \mathrm{~h}$. Annealing the $\mathrm{GC}$ increased the ORR activity significantly in acidic and alkaline solutions, as shown in Figure 14 (c), (d). In acidic solution, the Faradaic efficiency decreased by about $10 \%$ after annealing process. In alkaline solution, the selectivity was just as high as the unannealed electrode. For the purpose of comparison, we have also plotted the data for glassy carbon on Figure 8 . 
(a) $\mathrm{GC}$ in $0.1 \mathrm{M} \mathrm{HClO}_{4}$

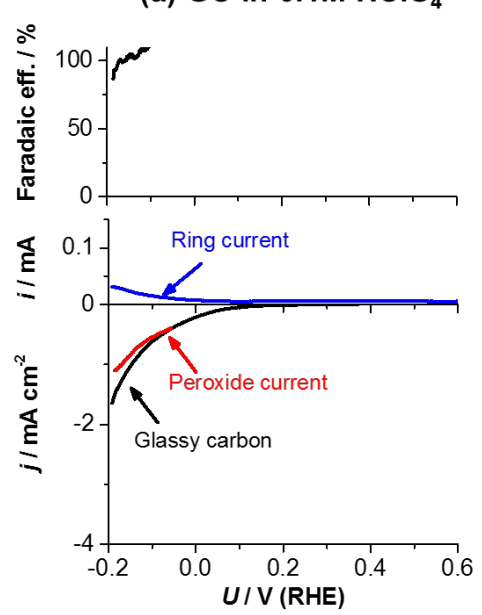

(c) Annealed GC in $0.1 \mathrm{M} \mathrm{HCIO}$

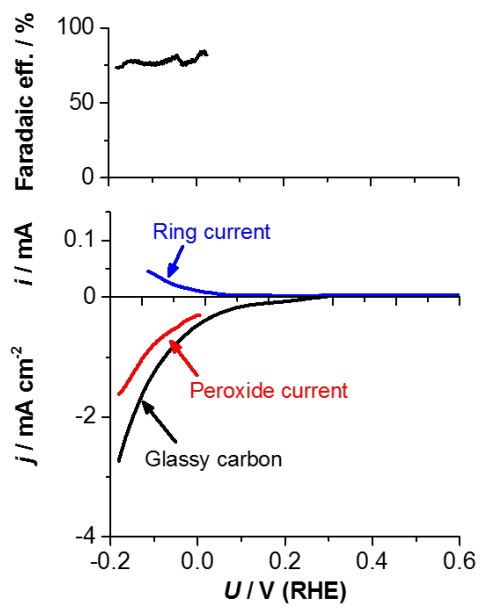

(b) GC in $0.1 \mathrm{M} \mathrm{KOH}$

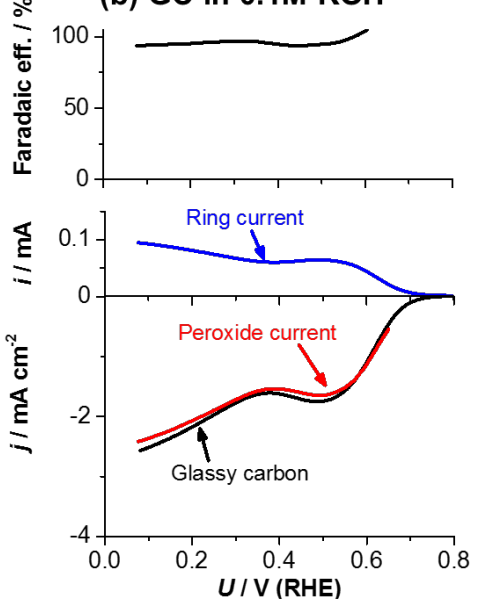

(d) Annealed GC in $0.1 \mathrm{M} \mathrm{KOH}$
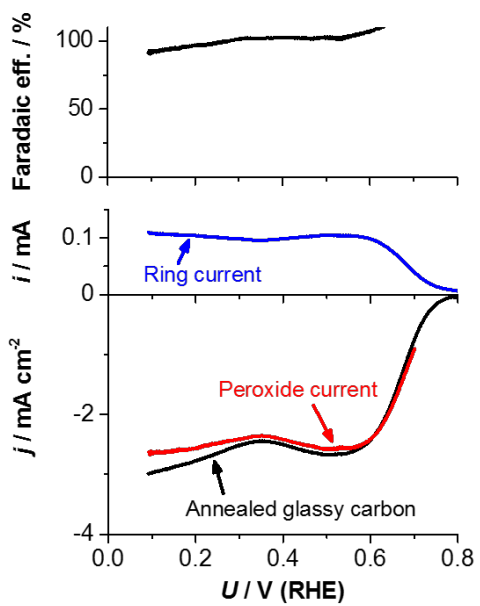

Figure 14. Oxygen reduction on (a), (b) GC and (c), (d) annealed GC using a rotating ring-disk electrode. (a), (c) Measurement in $0.1 \mathrm{M} \mathrm{HClO}_{4}$. (b), (d) Measurement in $0.1 \mathrm{M}$ $\mathrm{KOH}$. All data taken at $50 \mathrm{mV} / \mathrm{s}$ and $1600 \mathrm{rpm}$ at room temperature. Original data.

To summarize the above, in $0.1 \mathrm{M} \mathrm{KOH} \mathrm{Ag(pc),} \mathrm{Ag}-\mathrm{Hg}(\mathrm{pc})$ and $\mathrm{Pt}-\mathrm{Hg}(\mathrm{pc})$ exhibit much lower selectivity towards $\mathrm{H}_{2} \mathrm{O}_{2}$ production and higher activity to $\mathrm{H}_{2} \mathrm{O}$ production, relative to $0.1 \mathrm{M} \mathrm{HClO}_{4}$. Glassy carbon shows far higher activity in $0.1 \mathrm{KOH}$, relative to $0.1 \mathrm{HClO}_{4}$ without compromising on the selectivity. All these catalysts sit on the weak binding side of the volcano, as shown in Figure 9; in acid, the o verpotential would be limited by $* \mathrm{OOH}$ formation, equation 7 . Our observations are in agreement with other reports on weak binding catalysts, such as those based 


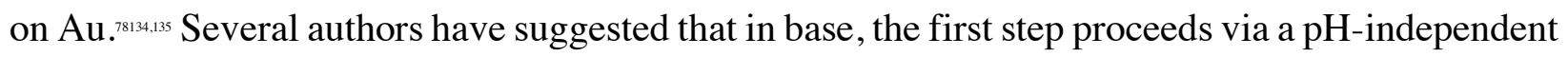
outer sphere mechanism involving the superoxide anion: $\mathrm{O}_{2}+\mathrm{e}^{-} \rightarrow \mathrm{O}_{2}^{-} \cdot{ }^{125.38 .447}$ Such a mechanism could allow weak binding catalysts to circumvent the $* \mathrm{OOH}$ formation step at sufficiently high $\mathrm{pH}$, explaining the higher activity. Even so, a very recent study from our laboratory suggests that such a mechanism may not be operative around the peak of the oxygen reduction volcano, not even for $\mathrm{Au}(100){ }^{127}$ Moreover, this superoxide-mediated pathway does not provide a trivial explanation to account for the poorer selectivity of these catalysts towards $\mathrm{H}_{2} \mathrm{O}_{2}$ production. As we discussed earlier, in acid, these catalysts show high selectivity to $\mathrm{H}_{2} \mathrm{O}_{2}$, even though there is a thermodynamic driving force towards producing $\mathrm{H}_{2} \mathrm{O}$. We propose that in base, the kinetic barriers preventing $* \mathrm{H}_{2} \mathrm{O}_{2}$ or $* \mathrm{OOH}$ dissociation are lower than in acid. As such, only the weakest binding catalysts, based on carbon (see Figure 9a), are able to preserve the O-O bond. The fundamental reason for this difference between acid and base is challenging to elucidate using current experimental ${ }^{4 s}$ and theoretical methods; ${ }^{; 49}$ however, on the basis of recent experiments on $\mathrm{H}_{2}$ evolution, we anticipate that it may be associated with the $\mathrm{pH}$-dependent reorganization of the electrochemical double layer. ${ }^{1 \mathrm{as}}$

From a technological perspective, it is striking that a non-toxic, inexpensive and abundant material based on carbon can catalyse $\mathrm{H}_{2} \mathrm{O}_{2}$ production so well in base. Indeed, Figure 8a suggests there is negligible room for improvement upon the activity and selectivity of annealed GC. As such, it could be tempting to replace the proton-conducting PEM electrolyte shown in Figure 6d with an anion exchange membrane (AEM). However, at present, such membranes do not constitute a mature technology: there is no commercially competitive AEM with sufficient stability and conductivity. ${ }^{150}$ Moreover, the $\mathrm{HO}_{2}$ anions may crossover from the cathode to anode in AEM, and be oxidized. Finally, we highlight that $\mathrm{H}_{2} \mathrm{O}_{2}$ is less stable in base, especially at $\mathrm{pH}>9{ }^{40}$ 
Consequently, we encourage researchers aiming to improve $\mathrm{H}_{2} \mathrm{O}_{2}$ catalysis to focus their efforts on acid solutions, more specifically on the PEM electrolyser type set-up shown in Figure 6d.

\section{MESOSCOPIC EFFECTS: Mass transport of product $\mathrm{H}_{2} \mathrm{O}_{2}$}

In the above discussion, we have thus far focused on microscopic effects that influence $\mathrm{H}_{2} \mathrm{O}_{2}$ production. However, it turns out that mesoscopic effects related to $\mathrm{H}_{2} \mathrm{O}_{2}$ are just as important in controlling selectivity. For instance, $\mathrm{Pt}$ is largely selective to the 4-electron pathway at potentials positive of $0.6 \mathrm{~V}$ RHE. However, at negative potentials, particularly when the surface is covered with $* \mathrm{H}$, it shows increasing selectivity towards $\mathrm{H}_{2} \mathrm{O}_{2}$. The selectivity is not only dependent on surface structure, ${ }^{126}$ but also on the transport of $\mathrm{H}_{2} \mathrm{O}_{2}$ away from the surface. Thus, on Pt, the Faradaic efficiency towards $\mathrm{H}_{2} \mathrm{O}_{2}$ increases under (i) conditions of forced convection, (ii) if the catalyst loading is low, or (iii) if microelectrodes are used..$^{151,152}$ Essentially, the extent to which $\mathrm{H}_{2} \mathrm{O}_{2}$ gets reduced further to $\mathrm{H}_{2} \mathrm{O}$ (c.f. equations (11) and (12)) is a function of its local concentration at the electrode surface. Under conditions of accelerated mass transport, $\mathrm{H}_{2} \mathrm{O}_{2}$ will move towards the bulk of the solution. Under conditions of poor mass transport, $\mathrm{H}_{2} \mathrm{O}_{2}$ will have a higher residence time in the vicinity of the electrode, hence increasing the probability that it re-adsorbs and is converted to $\mathrm{H}_{2} \mathrm{O}$. There are reports of similar mesoscopic phenomena on other catalysts, aside from Pt, in particular Fe-N/C. ${ }^{153}$ Most of the data we have presented in previous sections are based on RRDE experiments. However, we question whether such conditions are relevant in simulating real devices. To this end, in the current section, we present original data where we compare the Faradaic efficiencies of different catalysts in (i) a RRDE setup, (ii) a three electrodes set-up in 0.1 $\mathrm{M} \mathrm{HClO}_{4}$, and (iii) membrane electrode assembly (MEA) set-up. The mass transport characteristics of each system will be completely distinct. 
(a) RRDE

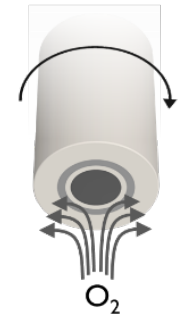

(b) GDE submerged in $0.1 \mathrm{M} \mathrm{HClO}_{4}$

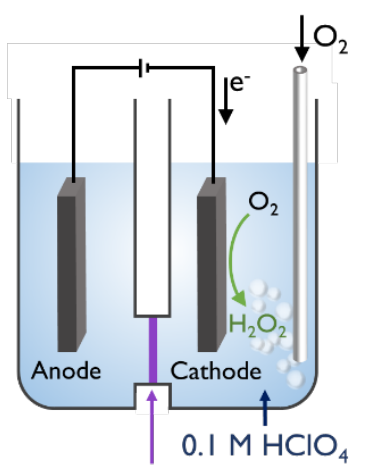

lon exchange membrane (c) Membrane electrode assembly (MEA)

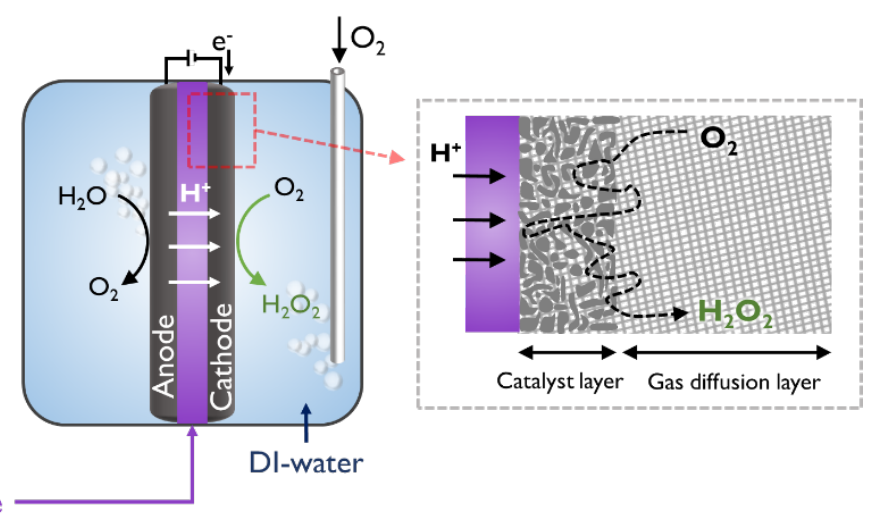

(d)

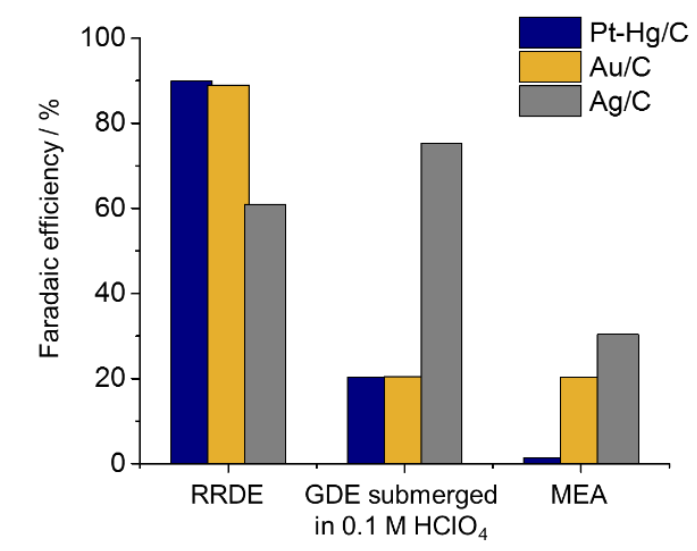

Figure 15. Schematics for (a) rotating ring disk electrode, (b) GDE submerged in $0.1 \mathrm{M}$ HClO4, using a three electrode system, and (c) MEA. (d) Faradaic efficiency in a,b and c. RRDE measurements were conducted in $\mathrm{O}_{2}$ saturated $0.1 \mathrm{M} \mathrm{HClO}_{4}$ with a rotating rate of $1600 \mathrm{rpm}$, highest Faradaic efficiency was selected. GDE submerged in $0.1 \mathrm{M} \mathrm{HClO}_{4}$ with $\mathrm{O}_{2}$ bubbling at a potential of $0.2 \mathrm{~V}$ vs RHE for $20 \mathrm{~min}$, Faradaic efficiency was determined by titration. MEA was submerged in DI-water and a total voltage of $1.6 \mathrm{~V}$ was held until $20 \mathrm{C}$ of charge were accumulated, Faradaic efficiency was determined by titration. All measurements were performed at room temperature, $25 \pm 1{ }^{\circ} \mathrm{C}$. Original data.

For the RRDE measurements (Figure 15a), we drop cas ted thin films of C-supported metal 
nanoparticle catalysts $\mathrm{Pt}-\mathrm{Hg} / \mathrm{C}, \mathrm{Ag} / \mathrm{C}$, and $\mathrm{Au} / \mathrm{C}$. We also drop-casted these supported catalysts onto gas diffusion electrodes (GDEs), which were submerged in $\mathrm{O}_{2}$ saturated $0.1 \mathrm{M} \mathrm{HClO}_{4}$ solution without external forced convection, other than $\mathrm{O}_{2}$ bubbling (Figure 15b). The same GDEs were also tested in MEA single cell set-ups (Figure 15c), which are submerged in pure $\mathrm{H}_{2} \mathrm{O}$, hence representative of real devices.

Figure 15d shows the outcome of our experiments. Au/C, which is $89 \%$ selective in RRDEs, only shows around $20 \%$ Faradaic efficiency in the GDE submerged in $0.1 \mathrm{M} \mathrm{HClO}_{4}$ and the MEA measurements. Ag shows high Faradaic efficiency levels of 60-75 \% in RRDE and the GDE submerged in $0.1 \mathrm{M} \mathrm{HClO}_{4}$; in the MEA it shows $30 \%$ Faradaic efficiency. Strikingly, Pt-Hg shows $90 \%$ Faradaic efficiency in RRDE measurements, $20 \%$ in the GDE submerged in $0.1 \mathrm{M}$ $\mathrm{HClO}_{4}$, and negligible efficiency in the MEA. The selectivity obtained in the MEA is much lower than in RRDE measurements; the GDE submerged in $0.1 \mathrm{M} \mathrm{HClO}_{4}$ is intermediate between the two other measurements, albeit closer to the MEA.

We attribute the differences between these measurements to the ease at which $\mathrm{H}_{2} \mathrm{O}_{2}$ is transported away from the catalyst surface. In the RRDE, $\mathrm{H}_{2} \mathrm{O}_{2}$ produced at the disk electrode is rapidly transported away from the disk electrode and oxidized at the ring electrode (Figure 15a), leading to low steady-state surface $\mathrm{H}_{2} \mathrm{O}_{2}$ concentrations. In the case of the MEA, protons will only be able to access the catalyst closest to the membrane, meaning that a large part of the $\mathrm{H}_{2} \mathrm{O}_{2}$ will be produced there; the $\mathrm{H}_{2} \mathrm{O}_{2}$ would then have to diffuse through the catalyst layer and the gas diffusion layer before it can go into the output water stream. We anticipate that the local concentration of $\mathrm{H}_{2} \mathrm{O}_{2}$ could be quite high close to the membrane; under such conditions, the kinetics of $\mathrm{H}_{2} \mathrm{O}_{2}$ reduction or chemical decomposition would be enhanced. Any solution-phase or electrode-bound impurities, as well as electrically isolated catalyst nanoparticles, would also catalyze the further 
reaction of the $\mathrm{H}_{2} \mathrm{O}_{2}$. The situation is highly analogous to the direct synthesis process, as described in Section 2. In the case of the GDE submerged in $0.1 \mathrm{M} \mathrm{HClO}_{4}$, a larger proportion of the catalyst would be accessible to protons than in the MEA; moreover, the $\mathrm{H}_{2} \mathrm{O}_{2}$ would not have to diffuse as far before it reaches the surrounding liquid electrolyte. As a consequence, in a MEA, mesoscopic transport effects prevent $\mathrm{Pt}-\mathrm{Hg}$ from yielding the high activity and selectivity exhibited in an RRDE.

We must emphasize that the data we present here on the GDE in $0.1 \mathrm{M} \mathrm{HClO}_{4}$ and the $\mathrm{MEA}$ are not completely optimized. The RRDE measurements are far easier to control; hence we consider that they provide an upper limit to the Faradaic efficiency. Further engineering of the catalyst layer in a MEA could yield higher selectivity. Even so, it is important to acknowledge that superior performance in an RRDE does not necessarily lead to superior performance in a real device..$^{154,155}$ Therefore, we advocate that researchers investigate $\mathrm{H}_{2} \mathrm{O}_{2}$ production under conditions more representative of real devices, using either MEAs or submerged GDEs in $0.1 \mathrm{M} \mathrm{HClO}_{4}$. To this end, we are currently investigating the catalysis of $\mathrm{H}_{2} \mathrm{O}_{2}$ production on high surface area carbon materials in submerged GDEs. However, our work on Hg-based alloys ${ }^{16,77}$ demonstrates that it is possible to achieve an unprecedented combination of activity, stability and selectivity. We anticipate that further research advances will eventually lead to a catalyst that works as well as Pd$\mathrm{Hg}$ in a real device, albeit without using $\mathrm{Hg}$ or precious metals.

\section{SUMMARY AND OUTLOOK}

We have elucidated the factors that control the catalysis of electrochemical $\mathrm{H}_{2} \mathrm{O}_{2}$ production. The surface electronic structure of the catalyst surface control the activity and the selectivity by tuning adsorption energy of the reaction intermediates. Weaker adsorption of the reaction intermediates 
provides higher $\mathrm{H}_{2} \mathrm{O}_{2}$ selectivity but decreases the overall activity. The geometric arrangement of surface atoms can also tune the selectivity. Isolated reactive atoms are less able to dissociate O-O bond than a contiguous ensemble of two or more atoms. The new theoretical calculations we include in this Perspective show that monoatomic sites yield a more optimal scaling relation between adsorbed oxygen and superhydroxyl; this phenomenon explains why they yield a better compromise between activity and stability.

Aside from the surface, the electrolyte composition, in particular the $\mathrm{pH}$, controls the activity and selectivity towards $\mathrm{H}_{2} \mathrm{O}_{2}$ production. In rotating ring disk electrode (RRDE) measurements, all the catalysts we tested showed higher activity for $\mathrm{O}_{2}$ reduction in $0.1 \mathrm{M} \mathrm{KOH}$ than $0.1 \mathrm{M} \mathrm{HClO}_{4}$; however, with the exception of glassy carbon, they were also less selective. Glassy carbon annealed in $\mathrm{O}_{2}$ was particularly active and selective in $0.1 \mathrm{M} \mathrm{KOH}$. Even so, we recommend that researchers focus their efforts on catalyzing $\mathrm{H}_{2} \mathrm{O}_{2}$ production under acid conditions: proton conducting polymeric membranes are far more technologically mature than their hydroxideconducting counterparts. ${ }^{120}$

Mesoscopic effects related to mass transport are also critical in determining $\mathrm{H}_{2} \mathrm{O}_{2}$ selectivity. It turns out that RRDE measurements provide an upper boundary to the Faradaic efficiency to $\mathrm{H}_{2} \mathrm{O}_{2}$, while real devices tend to underperform. Such phenomena call for model experiments to more accurately represent the conditions of real devices.

Not only should catalyst activity be maintained over the device lifetime, but also selectivity (Section 3.1). However, several catalysts with promising beginning-of-life performance, such as porphyrins, ${ }^{86,87}$ degrade over time. Our current insight in this area is rather limited. Future research should elucidate the mechanisms by which catalyst degradation occurs and develop strategies to prevent it from taking place. 
In summary, hydrogen peroxide is a versatile and non-toxic commodity chemical. Environmental concerns and the consequent legislation are set to increase the demand for $\mathrm{H}_{2} \mathrm{O}_{2}$ over the coming years. In particular, we emphasize that most applications require the $\mathrm{H}_{2} \mathrm{O}_{2}$ to be produced into an effluent of pure water. The decentralized electrochemical production $\mathrm{of}_{2} \mathrm{H}_{2}$ is especially attractive for this purpose.

More generally, the electrochemical production of $\mathrm{H}_{2} \mathrm{O}_{2}$ constitutes a pertinent example of a broader trend. We anticipate that the increased uptake and decreased cost of renewable electricity ${ }^{156}$ are set to transform the chemicals industry. We will soon be bestowed with a surplus of electrons, available for use as a key reactant for the decentralized synthesis of our most commonly used chemicals. ${ }^{157}$ The phenomena described herein are applicable to a broad range of electrochemical reactions of critical importance to industry, society and the environment. These include the partial

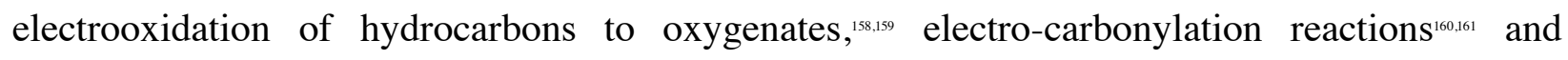
dinitrogen electroreduction to ammonia..$^{162,163}$ 
ASSOCIATED CONTENT

Supporting Information. Experimental and theoretical details are supplied as Supporting Information.

AUTHOR INFORMATION

Corresponding Author

*Ifan E. L. Stephens, i.stephens@imperial.ac.uk

\section{Author Contributions}

SY, AVC and IELS conceived and designed the experiments; AVC and SY performed the experiments. LS, LA and JR conceived the theoretical simulations; LS and LA performed the theoretical simulations. The manuscript was written through contributions of all authors. All authors have given approval to the final version of the manuscript.

\section{Funding Sources}

This work was supported by the Danmarks Innovationsfond, within the ProActivE project (516000003B).

\section{ACKNOWLEDGMENT}

This work was supported by the Danmarks Innovationsfond within the ProActivE project (516000003B) and Villum Foundation V-SUSTAIN grant 9455 to the Villum Center for the Science of Sustainable Fuels and Chemicals.

\section{CONFLICT OF INTEREST DISCLOSURE}

The authors, Arnau Verdaguer-Casadevall, Rasmus Frydendal,Jan Rossmeisl,Ib Chorkendorff and Ifan E. L. Stephens, have financial interests in HPNow. 


\section{REFERENCES}

(1) Hage, R.; Lienke, A. Applications of Transition-Metal Catalysts to Textile and Wood-Pulp Bleaching. Angew. Chemie - Int. Ed. 2005, 45, 206-222.

(2) Brillas, E.; Sirés, I.; Oturan, M. A. Electro-Fenton Process and Related Electrochemical Technologies Based on Fenton's Reaction Chemistry. Chem. Rev. 2009, 109, 6570-6631.

(3) Teles, J. H.; Hermans, I.; Franz, G.; Sheldon, R. A. Oxidation. In Ullmann's Encyclopedia of Industrial Chemistry; 2015; pp 1-103.

(4) Puértolas, B.; Hill, A. K.; García, T.; Solsona, B.; Torrente-Murciano, L. In-Situ Synthesis of Hydrogen Peroxide in Tandem with Selective Oxidation Reactions: A Mini-Review. Catal. Today 2015, 248, 115-127.

(5) Agarwal, N.; Freakley, S. J.; McVicker, R. U.; Althahban, S. M.; Dimitratos, N.; He, Q.; Morgan, D. J.; Jenkins, R. L.; Willock, D. J.; Taylor, S. H.; Kiely, C. J.; Hutchings, G. J. Aqueous Au-Pd Colloids Catalyze Selective $\mathrm{CH} 4$ Oxidation to $\mathrm{CH} 3 \mathrm{OH}$ with $\mathrm{O} 2$ under Mild Conditions. Science (80-. ). 2017, 358, 223-227.

(6) Hydrogen Peroxide Market Size By End-User (Paper \& Pulp, Chemical, Waste Water Treatment, Mining) https://www.gminsights.com/industry-analysis/hydrogen-peroxidemarket (accessed Nov 27, 2017).

(7) Ciriminna, R.; Albanese, L.; Meneguzzo, F.; Pagliaro, M. Hydrogen Peroxide: A Key Chemical for Today's Sustainable Development. ChemSusChem 2016, 9, 3374-3381.

(8) Yi, Y.; Wang, L.; Li, G.; Guo, H. A Review on Research Progress in the Direct Synthesis of Hydrogen Peroxide from Hydrogen and Oxygen: Noble-Metal Catalytic Method, Fuel- 
Cell Method and Plasma Method. Catal. Sci. Technol. 2016, 6, 1593-1610.

(9) Riedl, H.-J.; Pfleiderer, G. U.S. Patent. 2,158,525, 1939.

(10) Cient, C. Hydrogen Peroxide. In Ullmann's Encyclopedia of Industrial Chemistry; 2007; Vol. 1, pp 131-139.

(11) Campos-Martin, J. M.; Blanco-Brieva, G.; Fierro, J. L. G. Hydrogen Peroxide Synthesis: An Outlook beyond the Anthraquinone Process. Angew. Chemie - Int. Ed. 2006, 45, 69626984.

(12) Edwards, J. K.; Freakley, S. J.; Lewis, R. J.; Pritchard, J. C.; Hutchings, G. J. Advances in the Direct Synthesis of Hydrogen Peroxide from Hydrogen and Oxygen. Catal.Today 2015, 248, 3-9.

(13) Russo, V.; Tesser, R.; Santacesaria, E.; Di Serio, M. Chemical and Technical Aspects of Propene Oxide Production via Hydrogen Peroxide (HPPO Process). Ind. Eng. Chem. Res. 2013, 52, 1168-1178.

(14) Eul, W.; Moeller, A.; Steiner, N. Hydrogen Peroxide. In Kirk-Othmer Encyclopedia of Chemical Technology; 2001.

(15) Young, M. N.; Links, M. J.; Popat, S. C.; Rittmann, B. E.; Torres, C. I. Tailoring Microbial Electrochemical Cells for Production of Hydrogen Peroxide at High Concentrations and Efficiencies. ChemSusChem 2016, 1-9.

(16) Brandt, A. 20 years ago today, Helena shook, rattled and froze http://helenair.com/news/local/article_8984de1d-0792-5aad-8021-fba2af1f35f1.html 
(accessed Nov 21, 2017).

(17) M25

chaos

after

lorry

explosion

http://news.bbc.co.uk/2/hi/uk_news/england/london/4197500.stm (accessed Nov 20, 2017).

(18) Henkel, H.; Weber, W. Manufacture of Hydrogen Peroxid, 1913.

(19) Edwards, J. K.; Freakley, S. J.; Carley, A. F.; Kiely, C. J.; Hutchings, G. J. Strategies for Designing Supported Gold-Palladium Bimetallic Catalysts for the Direct Synthesis of Hydrogen Peroxide. Acc. Chem. Res. 2013, 47, 845-854.

(20) Lunsford, J. H. The Direct Formation of H2O2 from H2 and O2 over Palladium Catalysts. J. Catal. 2003, 216, 455-460.

(21) Edwards, J. K.; Solsona, B.; N, E. N.; Carley, A. F.; Herzing, A. A.; Kiely, C. J.; Hutchings, G. J. Switching Off Hydrogen Peroxide Hydrogenation in the Direct Synthesis Process. Science (80-. ). 2009, 323, 1037-1041.

(22) Freakley, S. J.; He, Q.; Harrhy, J. H.; Lu, L.; Crole, D. A.; Morgan, D. J.; Ntainjua, E. N.; Edwards, J. K.; Carley, A. F.; Borisevich, A. Y.; Kiely, C. J.; Hutchings, G. J. PalladiumTin Catalysts for the Direct Synthesis of H2O2 with High Selectivity. Science (80-. ). 2016, $351,965-968$.

(23) Edwards, J. K.; Thomas, A.; Carley, A. F.; Herzing, A. A.; Kiely, C. J.; Hutchings, G. J. $\mathrm{Au}-\mathrm{Pd}$ Supported Nanocrystals as Catalysts for the Direct Synthesis of Hydrogen Peroxide from $\mathrm{H}_{2}$ and $\mathrm{O}_{2}$. Green Chem. 2008, 10, 388-394. 
(24) Ntainjua N., E.; Edwards, J. K.; Carley, A. F.; Lopez-Sanchez, J. A.; Moulijn, J. A.; Herzing, A. A.; Kiely, C. J.; Hutchings, G. J. The Role of the Support in Achieving High Selectivity in the Direct Formation of Hydrogen Peroxide. Green Chem. 2008, 10, 1162.

(25) Edwards, J. K.; Carley, A. F.; Herzing, A. A.; Kiely, C. J.; Hutchings, G. J. Direct Synthesis of Hydrogen Peroxide from $\mathrm{H}_{2}$ and $\mathrm{O}_{2}$ Using Supported Au-Pd Catalysts. Faraday Discuss. 2008, 138, 225-239.

(26) Ntainjua N., E.; Piccinini, M.; Pritchard, J. C.; Edwards, J. K.; Carley, A. F.; Moulijn, J. A.; Hutchings, G. J. Effect of Halide and Acid Additives on the Direct Synthesis of Hydrogen Peroxide Using Supported Gold-Palladium Catalysts. ChemSusChem 2009, 2, 575-580.

(27) Edwards, J. K.; Pritchard, J.; Piccinini, M.; Shaw, G.; He, Q.; Carley, A. F.; Kiely, C. J.; Hutchings, G. J. The Effect of Heat Treatment on the Performance and Structure of CarbonSupported Au-Pd Catalysts for the Direct Synthesis of Hydrogen Peroxide. J. Catal. 2012, 292, 227-238.

(28) Rankin, R. B.; Greeley, J. Trends in Selective Hydrogen Peroxide Production on Transition Metal Surfaces from First Principles. ACS Catal. 2012, 2, 2664-2672.

(29) Ford, D. C.; Nilekar, A. U.; Xu, Y.; Mavrikakis, M. Partial and Complete Reduction of O2 by Hydrogen on Transition Metal Surfaces. Surf. Sci. 2010, 604, 1565-1575.

(30) Burch, R.; Ellis, P. R. An Investigation of Alternative Catalytic Approaches for the Direct Synthesis of Hydrogen Peroxide from Hydrogen and Oxygen. Appl. Catal.B Environ. 2003, $42,203-211$.

(31) Chinta, S.; Lunsford, J. H. A Mechanistic Study of $\mathrm{H} 2 \mathrm{O} 2$ and H2O Formation from $\mathrm{H} 2$ and 
O2 Catalyzed by Palladium in an Aqueous Medium. J. Catal. 2004, 225, 249-255.

(32) Choudhary, V. R.; Samanta, C. Role of Chloride or Bromide Anions and Protons for Promoting the Selective Oxidation of $\mathrm{H} 2$ by $\mathrm{O} 2$ to $\mathrm{H} 2 \mathrm{O} 2$ over Supported Pd Catalysts in an Aqueous Medium. J. Catal. 2006, 238, 28-38.

(33) Liu, Q.; Lunsford, J. H. The Roles of Chloride Ions in the Direct Formation of H2O 2 from $\mathrm{H} 2$ and $\mathrm{O} 2$ over a $\mathrm{Pd} / \mathrm{SiO} 2$ Catalyst in a H2SO4/ethanol System. J. Catal. 2006, 239, 237 243.

(34) Ford, J. Cardiff sets gold standard for catalysis research https://www.theengineer.co.uk/issues/june-2014-online/cardiff-sets-gold-standard-forcatalysis-research/ (accessed Nov 28, 2017).

(35) Gassie, L. W.; Englehardt, J. D. Advanced Oxidation and Disinfection Processes for Onsite Net-Zero Greywater Reuse: A Review. Water Res. 2017, 125, 384-399.

(36) Teh, X. Y.; Poh, P. E.; Gouwanda, D.; Chong, M. N. Decentralized Light Greywater Treatment Using Aerobic Digestion and Hydrogen Peroxide Disinfection for Non-Potable Reuse. J. Clean. Prod. 2015, 99, 305-311.

(37) Jones, C. W. Applications of Hydrogen Peroxide and Derivatives; Royal Society of Chemistry, 1999.

(38) Berl, E. A New Cathodic Process for the Production of H2O2. Trans. Electrochem. Soc. 1939, 76, 359-369.

(39) Foller, P. C.; Bombard, R. T. Processes for the Production of Mixtures of Caustic Soda and 
Hydrogen-Peroxide Via the Reduction of Oxygen. J. Appl. Electrochem. 1995, 25, 613627.

(40) Qiang, Z. M.; Chang, J. H.; Huang, C. P. Electrochemical Generation of Hydrogen Peroxide from Dissolved Oxygen in Acidic Solutions. Water Res. 2002, 36, 85-94.

(41) Zhou, M.; Yu, Q.; Lei, L.; Barton, G. Electro-Fenton Method for the Removal of Methyl Red in an Efficient Electrochemical System. Sep. Purif. Technol. 2007, 57, 380-387.

(42) Pajootan, E.; Arami, M.; Rahimdokht, M. Discoloration of Wastewater in a Continuous Electro-Fenton Process Using Modified Graphite Electrode with Multi-Walled Carbon Nanotubes/surfactant. Sep. Purif. Technol. 2014, 130, 34-44.

(43) Lei, H.; Li, H.; Li, Z.; Li, Z.; Chen, K.; Zhang, X.; Wang, H. Electro-Fenton Degradation of Cationic Red X-GRL Using an Activated Carbon Fiber Cathode. Process Saf. Environ. Prot. 2010, 88, 431-438.

(44) Ledezma Estrada, A.; Li, Y. Y.; Wang, A. Biodegradability Enhancement of Wastewater Containing Cefalexin by Means of the Electro-Fenton Oxidation Process. J. Hazard. Mater. 2012, 227-228, 41-48.

(45) Sheng, Y.; Song, S.; Wang, X.; Song, L.; Wang, C.; Sun, H.; Niu, X. Electrogeneration of Hydrogen Peroxide on a Novel Highly Effective Acetylene Black-PTFE Cathode with PTFE Film. Electrochim. Acta 2011, 56, 8651-8656.

Özcan, A.; Şahin, Y.; Savaş Koparal, A.; Oturan, M. A. Carbon Sponge as a New Cathode Material for the Electro-Fenton Process: Comparison with Carbon Felt Cathode and Application to Degradation of Synthetic Dye Basic Blue 3 in Aqueous Medium. J. 
Electroanal. Chem. 2008, 616, 71-78.

(47) Xia, G.; Lu, Y.; Xu, H. An Energy-Saving Production of Hydrogen Peroxide via Oxygen Reduction for Electro-Fenton Using Electrochemically Modified Polyacrylonitrile-Based Carbon Fiber Brush Cathode. Sep. Purif. Technol. 2015, 156, 553-560.

(48) Xia, G.; Lu, Y.; Gao, X.; Gao, C.; Xu, H. B. Electro-Fenton Degradation of Methylene Blue Using Polyacrylonitrile-Based Carbon Fiber Brush Cathode. Clean - Soil, Air, Water 2015, $43,229-236$.

(49) Zhang, X.; Fu, J.; Zhang, Y.; Lei, L. A Nitrogen Functionalized Carbon Nanotube Cathode for Highly Efficient Electrocatalytic Generation of $\mathrm{H} 2 \mathrm{O} 2$ in Electro-Fenton System. Sep. Purif. Technol. 2008, 64, 116-123.

Zhou, L.; Zhou, M.; Hu, Z.; Bi, Z.; Serrano, K. G. Chemically Modified Graphite Felt as an Efficient Cathode in Electro-Fenton for P-Nitrophenol Degradation. Electrochim. Acta 2014, 140, 376-383.

Zhang, X.; Lei, L.; Xia, B.; Zhang, Y.; Fu, J. Oxidization of Carbon Nanotubes through Hydroxyl Radical Induced by Pulsed O2 Plasma and Its Application for O2 Reduction in Electro-Fenton. Electrochim. Acta 2009, 54, 2810-2817.

(52) Mousset, E.; Wang, Z.; Lefebvre, O. Electro-Fenton for Control and Removal of Micropollutants - Process Optimization and Energy Efficiency. Water Sci. Technol. 2016, 74, 2068-2074.

(53) Rabaey, K.; Rozendal, R. A. Microbial Electrosynthesis - Revisiting the Electrical Route for Microbial Production. Nat. Rev. Microbiol. 2010, 8, 706-716. 
(54) Modin, O.; Fukushi, K. Development and Testing of Bioelectrochemical Reactors Converting Wastewater Organics into Hydrogen Peroxide. Water Sci. Technol. 2012, 66, 831-836.

(55) Sim, J.; An, J.; Elbeshbishy, E.; Ryu, H.; Lee, H. S. Characterization and Optimization of Cathodic Conditions for $\mathrm{H} 2 \mathrm{O} 2$ Synthesis in Microbial Electrochemical Cells. Bioresour. Technol. 2015, 195, 31-36.

Chen, J. Y.; Li, N.; Zhao, L. Three-Dimensional Electrode Microbial Fuel Cell for Hydrogen Peroxide Synthesis Coupled to Wastewater Treatment. J. Power Sources 2014, $254,316-322$.

Rozendal, R. A.; Leone, E.; Keller, J.; Rabaey, K. Efficient Hydrogen Peroxide Generation from Organic Matter in a Bioelectrochemical System. Electrochem. commun. 2009, 11, $1752-1755$.

Li, N.; An, J.; Zhou, L.; Li, T.; Li, J.; Feng, C.; Wang, X. A Novel Carbon Black Graphite Hybrid Air-Cathode for Efficient Hydrogen Peroxide Production in Bioelectrochemical Systems. J. Power Sources 2016, 306, 495-502.

(59) Modin, O.; Fukushi, K. Production of High Concentrations of $\mathrm{H} 2 \mathrm{O} 2$ in a Bioelectrochemical Reactor Fed with Real Municipal Wastewater. Environ. Technol. 2013, $34,1-6$.

(60) Viswanathan, V.; Hansen, H. A.; Nørskov, J. K. Selective Electrochemical Generation of Hydrogen Peroxide from Water Oxidation. J. Phys. Chem. Lett. 2015, 6, 4224-4228.

(61) Shi, X.; Siahrostami, S.; Li, G. L.; Zhang, Y.; Chakthranont, P.; Studt, F.; Jaramillo, T. F.; 
Zheng, X.; Nørskov, J. K. Understanding Activity Trends in Electrochemical Water Oxidation to Form Hydrogen Peroxide. Nat. Commun. 2017, 8, 1-12.

(62) Otsuka, K.; Yamanaka, I. One Step Synthesis of Hydrogen Peroxide Through Fuel Cell Reaction. Electrochim. Acta 1990, 35, 319-322.

(63) Yamanaka, I.; Onizawa, T.; Takenaka, S.; Otsuka, K. Direct and Continuous Production of Hydrogen Peroxide with 93\% Selectivity Using a Fuel-Cell System. Angew. Chemie - Int. Ed. 2003, 42, 3653-3655.

(64) Yamanaka, I.; Hashimoto, T.; Ichihashi, R.; Otsuka, K. Direct Synthesis of H2O2 Acid Solutions on Carbon Cathode Prepared from Activated Carbon and Vapor-GrowingCarbon-Fiber by a H2/O2 Fuel Cell. Electrochim. Acta 2008, 53, 4824-4832.

(65) Yamanaka, I.; Murayama, T. Neutral H2O2 Synthesis by Electrolysis of Water and O2. Angew. Chemie - Int. Ed. 2008, 47, 1900-1902.

(66) Murayama, T.; Yamanaka, I. Electrosynthesis of Neutral H2O2 Solution from O 2 and Water at a Mixed Carbon Cathode Using an Exposed Solid-Polymer-Electrolyte Electrolysis Cell. J. Phys. Chem. C 2011, 115, 5792-5799.

(67) Yamanaka, I.; Tazawa, S.; Murayama, T.; Ichihashi, R.; Hanaizumi, N. Catalytic Synthesis of Neutral $\mathrm{H}_{2} \mathrm{O}_{2}$ Solutions from $\mathrm{O}_{2}$ and $\mathrm{H}_{2}$ by a Fuel Cell Reaction. ChemSusChem 2008, $1,988-992$.

(68) Yamanaka, I.; Tazawa, S.; Murayama, T.; Iwasaki, T.; Takenaka, S. Catalytic Synthesis of Neutral Hydrogen Peroxide at a CoN2Cx Cathode of a Polymer Electrolyte Membrane Fuel Cell (PEMFC). ChemSusChem 2010, 3, 59-62. 
(69) Yamanaka, I.; Ichihashi, R.; Iwasaki, T.; Nishimura, N.; Murayama, T.; Ueda, W.; Takenaka, S. Electrocatalysis of Heat-Treated Cobalt-Porphyrin/carbon for Hydrogen Peroxide Formation. Electrochim. Acta 2013, 108, 321-329.

(70) Iwasaki, T.; Masuda, Y.; Ogihara, H.; Yamanaka, I. Direct Synthesis of Pure H2O2 Aqueous Solution by CoTPP/Ketjen-Black Electrocatalyst and the Fuel Cell Reactor. Electrocatalysis 2017, 9, 236-242.

(71) Yamanaka, I.; Onizawa, T.; Suzuki, H.; Hanaizumi, N.; Nishimura, N. Study of Direct Synthesis of Hydrogen Peroxide Acid Solutions at a Heat-Treated $\mathrm{MnCl}$ - Porphyrin / Activated Carbon Cathode from $\mathrm{H} 2$ and O2. J. Phys. Chem. C 2012, 116, 4572-4583.

(72) Li, W.; Bonakdarpour, A.; Gyenge, E.; Wilkinson, D. P. Drinking Water Purification by Electrosynthesis of Hydrogen Peroxide in a Power-Producing PEM Fuel Cell. ChemSusChem 2013, 6, 2137-2143.

(73) Sánchez-Sánchez, C.; Bard, A. Hydrogen Peroxide Production in the Oxygen Reduction Reaction at Different Electrocatalysts as Quantified by Scanning Electrochemical Microscopy. Anal. Chem. 2009, 81, 8094-8100.

(74) Schmidt, T. J.; Gasteiger, H. A.; Stäb, G. D.; Urban, P. M.; Kolb, D. M.; Behm, R. J. Characterization of High-Surface-Area Electrocatalysts Using a Rotating Disk Electrode Configuration. J. Electrochem. Soc. 1998, 145, 2354-2358.

(75) Paulus, U. A.; Schmidt, T. J.; Gasteiger, H. A.; Behm, R. J. Oxygen Reduction on a HighSurface Area Pt/Vulcan Carbon Catalyst: A Thin-Film Rotating Ring-Disk Electrode Study. J. Electroanal. Chem. 2001, 495, 134-145. 
(76) Siahrostami, S.; Verdaguer-Casadevall, A.; Karamad, M.; Deiana, D.; Malacrida, P.; Wickman, B.; Escudero-Escribano, M.; Paoli, E. a; Frydendal, R.; Hansen, T. W.; Chorkendorff, I.; Stephens, I. E. L.; Rossmeisl, J. Enabling Direct H2O2 Production through Rational Electrocatalyst Design. Nat. Mater. 2013, 12, 1137-1143.

(77) Verdaguer-casadevall, A.; Deiana, D.; Karamad, M.; Siahrostami, S.; Hansen, T. W.; Rossmeisl, J.; Chorkendorff, I.; Stephens, I. E. L. Trends in the Electrochemical Synthesis of H2O2 : Enhancing Activity and Selectivity by Electrocatalytic Site Engineering Trends in the Electrochemical Synthesis of $\mathrm{H}_{2} \mathrm{O} 2$ : Enhancing Activity and Selectivity by Electrocatalytic Site Engineering. Nano Lett. 2014, 14, 1603-1608.

(78) Jirkovský, J. S.; Halasa, M.; Schiffrin, D. J. Kinetics of Electrocatalytic Reduction of Oxygen and Hydrogen Peroxide on Dispersed Gold Nanoparticles. Phys. Chem. Chem. Phys. 2010, 12, 8042-8052.

(79) Jirkovsky, J. S.; Panas, I.; Ahlberg, E.; Halasa, M.; Romani, S.; Schiffrin, D. J. Single Atom Hot-Spots at Au-Pd Nanoalloys for Electrocatalytic H2 O2 Production. J. Am. Chem. Soc. 2011, 133, 19432-19441.

(80) Pizzutilo, E.; Kasian, O.; Choi, C. H.; Cherevko, S.; Hutchings, G. J.; Mayrhofer, K. J. J.; Freakley, S. J. Electrocatalytic Synthesis of Hydrogen Peroxide on Au-Pd Nanoparticles: From Fundamentals to Continuous Production. Chem. Phys. Lett. 2017, 683, 436-442.

(81) Yang, S.; Kim, J.; Tak, Y. J.; Soon, A.; Lee, H. Single-Atom Catalyst of Platinum Supported on Titanium Nitride for Selective Electrochemical Reactions. Angew. Chemie - Int. Ed. 2016, 55, 2058-2062. 
(82) Choi, C. H.; Kim, M.; Kwon, H. C.; Cho, S. J.; Yun, S.; Kim, H.-T.; Mayrhofer, K. J. J.; Kim, H.; Choi, M. Tuning Selectivity of Electrochemical Reactions by Atomically Dispersed Platinum Catalyst. Nat. Commun. 2016, 7, 10922.

(83) Campos, M.; Siriwatcharapiboon, W.; Potter, R. J.; Horswell, S. L. Selectivity of CobaltBased Catalysts towards Hydrogen Peroxide Formation during the Reduction of Oxygen. Catal. Today 2013, 202, 135-143.

(84) Wang, A.; Bonakdarpour, A.; Wilkinson, D. P.; Gyenge, E. Novel Organic Redox Catalyst for the Electroreduction of Oxygen to Hydrogen Peroxide. Electrochim. Acta 2012, 66, $222-229$.

(85) Hasché, F.; Oezaslan, M.; Strasser, P.; Fellinger, T. P. Electrocatalytic Hydrogen Peroxide Formation on Mesoporous Non-Metal Nitrogen-Doped Carbon Catalyst. J. Energy Chem. 2016, 25, 251-257.

(86) Blomquist, J.; Helgeson, U.; Moberg, L. C.; Johansson, L. Y.; Larsson, R. Simultaneous Electrochemical and Mössbauer Measurements on Polymeric Iron Phthalocyanine Oxygen Electrodes. Electrochim. Acta 1982, 27, 1453-1460.

(87) Wiesener, K. N4-Chelates as Electrocatalyst for Cathodic Oxygen Reduction. Electrochim. Acta 1986, 31, 1073-1078.

(88) Vasudevan, P.; Santosh; Mann, N.; Tyagi, S. Transition Metal Complexes of Porphyrins and Phthalocyanines as Electrocatalysts for Dioxygen Reduction. Transit.Met.Chem. 1990, $15,81-90$.

(89) Jinnouchi, R.; Kodama, K.; Hatanaka, T.; Morimoto, Y. First Principles Based Mean Field 
Model for Oxygen Reduction Reaction. Phys. Chem. Chem. Phys. 2011, 13, 21070.

(90) Janik, M. J.; Taylor, C. D.; Neurock, M. First-Principles Analysis of the Initial Electroreduction Steps of Oxygen over Pt(111). J. Electrochem. Soc. 2009, 156, B126.

(91) Nørskov, J. K.; Rossmeisl, J.; Logadottir, A.; Lindqvist, L.; Kitchin, J. R.; Bligaard, T.; Jónsson, H. Origin of the Overpotential for Oxygen Reduction at a Fuel-Cell Cathode. $J$. Phys. Chem. B 2004, 108, 17886-17892.

(92) Viswanathan, V.; Hansen, H. A.; Rossmeisl, J.; Nørskov, J. K. Unifying the 2e- and 4eReduction of Oxygen on Metal Surfaces. J. Phys. Chem. Lett. 2012, 3, 2948-2951.

(93) Bandarenka, A. S.; Hansen, H. A.; Rossmeisl, J.; Stephens, I. E. L. Elucidating the Activity of Stepped Pt Single Crystals for Oxygen Reduction. Phys. Chem. Chem. Phys. 2014, 16, 13625 .

(94) Stamenkovic, V.; Mun, B. S.; Mayrhofer, K. J. J.; Ross, P. N.; Markovic, N. M.; Rossmeisl, J.; Greeley, J.; Nørskov, J. K. Changing the Activity of Electrocatalysts for Oxygen Reduction by Tuning the Surface Electronic Structure. Angew. Chemie 2006, 118, 29632967.

(95) Tripković, V.; Skúlason, E.; Siahrostami, S.; Nørskov, J. K.; Rossmeisl, J. The Oxygen Reduction Reaction Mechanism on Pt(1 11 1) from Density Functional Theory Calculations. Electrochim. Acta 2010, 55, 7975-7981.

(96) Calle-Vallejo, F.; Krabbe, A.; García-Lastra, J. M. How Covalence Breaks AdsorptionEnergy Scaling Relations and Solvation Restores Them. Chem. Sci. 2017, 8, 124-130. 
(97) Collman, J. P.; Denisevich, P.; Konai, Y.; Marrocco, M.; Koval, C.; Anson, F. C. Electrode Catalysis of the Four-Electron Reduction of Oxygen to Water by Dicobalt Face-to-Face Porphyrins. J. Am. Chem. Soc. 1980, 102, 6027-6036.

(98) Barros, W. R. P.; Reis, R. M.; Rocha, R. S.; Lanza, M. R. V. Electrogeneration of Hydrogen Peroxide in Acidic Medium Using Gas Diffusion Electrodes Modified with Cobalt (II) Phthalocyanine. Electrochim. Acta 2013, 104, 12-18.

(99) Wu, G.; More, K. L.; Johnston, C. M.; Zelenay, P. High-Performance Electrocatalysts for Oxygen Reduction Derived from Polyaniline, Iron, and Cobalt. Science (80-. ). 2011, 332, 443-448.

(100) Zitolo, A.; Goellner, V.; Armel, V.; Sougrati, M.-T.; Mineva, T.; Stievano, L.; Fonda, E.; Jaouen, F. Identification of Catalytic Sites for Oxygen Reduction in Iron- and NitrogenDoped Graphene Materials. Nat. Mater. 2015, 14, 937-942.

(101) Lefèvre, M.; Proietti, E.; Jaouen, F.; Dodelet, J.-P. Iron-Based Catalysts with Improved Oxygen Reduction Activity in Polymer Electrolyte Fuel Cells. Science (80-. ). 2009, 324, 71-74.

(102) Kramm, U. I.; Herranz, J.; Larouche, N.; Arruda, T. M.; Lefèvre, M.; Jaouen, F.; Bogdanoff, P.; Fiechter, S.; Abs-Wurmbach, I.; Mukerjee, S.; Dodelet, J.-P. Structure of the Catalytic Sites in Fe/N/C-Catalysts for O2-Reduction in PEM Fuel Cells. Phys. Chem. Chem. Phys. 2012, 14, 11673.

(103) Malko, D.; Kucernak, A.; Lopes, T. In Situ Electrochemical Quantification of Active Sites in Fe-N/C Non-Precious Metal Catalysts. Nat. Commun. 2016, 7, 1-7. 
(104) Zagal, J.; Páez, M.; Tanaka, A. A.; dos Santos, J. R.; Linkous, C. A. Electrocatalytic Activity of Metal Phthalocyanines for Oxygen Reduction. J. Electroanal. Chem. 1992, 339, $13-30$.

(105) Chen, R.; Li, H.; Chu, D.; Wang, G. Unraveling Oxygen Reduction Reaction Mechanisms on Carbon-Supported Fe-Phthalocyanine and Co-Phthalocyanine Catalysts in Alkaline Solutions Report Documentation Page Unraveling Oxygen Reduction Reaction Mechanisms on Richard G . Lugar Center for Renewable. J. Phys. Chem. C 2009, 113, 20689-20697.

(106) Sun, S.; Jiang, N.; Xia, D. Density Functional Theory Study of the Oxygen Reduction Reaction on Metalloporphyrins and Metallophthalocyanines. J. Phys. Chem. C 2011, 115, 9511-9517.

(107) Song, E.; Shi, C.; Anson, F. C. Comparison of the Behavior of Several Cobalt Porphyrins as Electrocatalysts for the Reduction of O2 at Graphite Electrodes. Langmuir 1998, 14, $4315-4321$.

(108) Ziegelbauer, J. M.; Olson, T. S.; Pylypenko, S.; Alamgir, F.; Jaye, C.; Atanassov, P.; Mukerjee, S. Direct Spectroscopic Observation of the Structural Origin of Peroxide Generation from Co-Based Pyrolyzed Porphyrins for ORR Applications. J. Phys. Chem. C 2008, 112, 8839-8849.

(109) Yamada, Y.; Fukunishi, Y.; Yamazaki, S.; Fukuzumi, S. Hydrogen Peroxide as Sustainable Fuel: Electrocatalysts for Production with a Solar Cell and Decomposition with a Fuel Cell. Chem. Commun. 2010, 46, 7334. 
(110) Bouwkamp-Wijnoltz, A. L.; Visscher, W.; van Veen, J. A. R. The Selectivity of Oxygen Reduction by Pyrolysed Iron Porphyrin Supported on Carbon. Electrochim. Acta 1998, 43, $3141-3152$.

(111) Guillet, N.; Roué, L.; Marcotte, S.; Villers, D.; Dodelet, J. P.; Chhim, N.; Trévin, S. Electrogeneration of Hydrogen Peroxide in Acid Medium Using Pyrolyzed Cobalt-Based Catalysts: Influence of the Cobalt Content on the Electrode Performance. J. Appl. Electrochem. 2006, 36, 863-870.

(112) Bezerra, C. W. B.; Zhang, L.; Lee, K. C.; Liu, H. S.; Marques, A. L. B.; Marques, E. P.; Wang, H. J.; Zhang, J. J. A Review of Fe-N/C and Co-N/C Catalysts for the Oxygen Reduction Reaction. Electrochim. Acta 2008, 53, 4937-4951.

(113) Wu, H. L.; Yau, S.; Zei, M. S. Crystalline Alloys Produced by Mercury Electrodeposition on Pt(111) Electrode at Room Temperature. Electrochim. Acta 2008, 53, 5961-5967.

(114) Choi, C. H.; Kwon, H. C.; Yook, S.; Shin, H.; Kim, H.; Choi, M. Hydrogen Peroxide Synthesis via Enhanced Two - Electron Oxygen Reduction Pathway on Carbon - Coated Pt Surface. J. Phys. Chem. C 2014, 118, 30063-30070.

(115) Yang, S.; Tak, Y. J.; Kim, J.; Soon, A.; Lee, H. Support Effect in Single-Atom Platinum Catalyst for Electrochemical Oxygen Reduction. ACS Catal. 2016, acscatal.6b02899.

(116) Valim, R. B.; Reis, R. M.; Castro, P. S.; Lima, A. S.; Rocha, R. S.; Bertotti, M.; Lanza, M. R. V. Electrogeneration of Hydrogen Peroxide in Gas Diffusion Electrodes Modified with Tert-Butyl-Anthraquinone on Carbon Black Support. Carbon N. Y. 2013, 61, 236-244.

(117) Forti, J. C.; Rocha, R. S.; Lanza, M. R. V; Bertazzoli, R. Electrochemical Synthesis of 
Hydrogen Peroxide on Oxygen-Fed graphite/PTFE Electrodes Modified by 2Ethylanthraquinone. J. Electroanal. Chem. 2007, 601, 63-67.

(118) Gyenge, E. L.; Oloman, C. W. Electrosynthesis of Hydrogen Peroxide in Acidic Solutions by Mediated Oxygen Reduction in a Three-Phase (Aqueous/organic/gaseous) System Part I: Emulsion Structure, Electrode Kinetics and Batch Electrolysis. J. Appl. Electrochem. 2003, 33, 655-663.

(119) Gyenge, E. L.; Oloman, C. W. Electrosynthesis of Hydrogen Peroxide in Acidic Solutions by Mediated Oxygen Reduction in a Three-Phase (Aqueous/organic/gaseous) System Part II: Experiments in Flow-by Fixed-Bed Electrochemical Cells with Three-Phase Flow. $J$. Appl. Electrochem. 2003, 33, 665-674.

(120) Varcoe, J. R.; Atanassov, P.; Dekel, D. R.; Herring, A. M.; Hickner, M. A.; Kohl, P. A.; Kucernak, A. R.; Mustain, W. E.; Nijmeijer, K.; Scott, K.; Xu, T.; Zhuang, L. AnionExchange Membranes in Electrochemical Energy Systems. Energy Environ. Sci. 2014, 7, $3135-3191$.

(121) Holewinski, A.; Idrobo, J.-C.; Linic, S. High-Performance Ag-Co Alloy Catalysts for Electrochemical Oxygen Reduction. Nat. Chem. 2014, 6, 828-834.

(122) Suntivich, J.; Gasteiger, H. A.; Yabuuchi, N.; Shao-Horn, Y. Electrocatalytic Measurement Methodology of Oxide Catalysts Using a Thin-Film Rotating Disk Electrode. $J$. Electrochem. Soc. 2010, 157, B1263.

(123) Rossmeisl, J.; Chan, K.; Ahmed, R.; Tripković, V.; Björketun, M. E. pH in Atomic Scale Simulations of Electrochemical Interfaces. Phys. Chem. Chem. Phys. 2013, 15, 10321. 
(124) Hansen, H. A.; Rossmeisl, J.; Nørskov, J. K. Surface Pourbaix Diagrams and Oxygen Reduction Activity of Pt, Ag and Ni(111) Surfaces Studied by DFT. Phys. Chem. Chem. Phys. 2008, 10, 3722-3730.

(125) Koper, M. T. M. Theory of Multiple Proton-electron Transfer Reactions and Its Implications for Electrocatalysis. Chem. Sci. 2013, 4, 2710.

(126) Stamenkovic, V. R.; Fowler, B.; Mun, B. S.; Wang, G.; Ross, P. N.; Lucas, C. A.; Marković, N. M. Improved Oxygen Reduction Activity on Pt3Ni(111) via Increased Surface Site Availability. Science (80-. ). 2007, 315, 493-497.

(127) Jensen, K. D.; Tymoczko, J.; Rossmeisl, J.; Bandarenka, A.; Chorkendorff, I.; EscuderoEscribano, M.; Stephens, I. E. L. Elucidation of the Oxygen Reduction Volcano in Alkaline Media Using a Copper-Platinum(111) Alloy. Angew. Chemie Int. Ed. 2018, 57, 2800-2805.

(128) Rizo, R.; Herrero, E.; Feliu, J. M. Oxygen Reduction Reaction on Stepped Platinum Surfaces in Alkaline Media. Phys. Chem. Chem. Phys. 2013, 15, 15416.

(129) Nesselberger, M.; Ashton, S.; Meier, J. C.; Katsounaros, I.; Mayrhofer, K. J. J.; Arenz, M. The Particle Size Effect on the Oxygen Reduction Reaction Activity of Pt Catalysts: Influence of Electrolyte and Relation to Single Crystal Models. J. Am. Chem. Soc. 2011, $133,17428-17433$.

(130) Staszak-Jirkovský, J.; Subbaraman, R.; Strmcnik, D.; Harrison, K. L.; Diesendruck, C. E.; Assary, R.; Frank, O.; Kobr, L.; Wiberg, G. K. H.; Genorio, B.; Connell, J. G.; Lopes, P. P.; Stamenkovic, V. R.; Curtiss, L.; Moore, J. S.; Zavadil, K. R.; Markovic, N. M. Water as a Promoter and Catalyst for Dioxygen Electrochemistry in Aqueous and Organic Media. 
ACS Catal. 2015, 5, 6600-6607.

(131) Strmcnik, D.; Kodama, K.; van der Vliet, D.; Greeley, J.; Stamenkovic, V. R.; Marković, N. M. The Role of Non-Covalent Interactions in Electrocatalytic Fuel-Cell Reactions on Platinum. Nat. Chem. 2009, 1, 466.

(132) Spendelow, J. S.; Wieckowski, A. Electrocatalysis of Oxygen Reduction and Small Alcohol Oxidation in Alkaline Media. Phys. Chem. Chem. Phys. 2007, 9, 2654.

(133) Blizanac, B. B.; Ross, P. N.; Markovic, N. M. Oxygen Electroreduction on Ag(1 11 1): The pH Effect. Electrochim. Acta 2007, 52, 2264-2271.

(134) Blizanac, B. B.; Lucas, C. A.; Gallagher, M. E.; Arenz, M.; Ross, P. N.; Marković, N. M. Anion Adsorption, CO Oxidation, and Oxygen Reduction Reaction on a $\mathrm{Au}(100)$ Surface: The pH Effect. J. Phys. Chem. B 2004, 108, 625-634.

(135) Schmidt, T. J.; Stamenkovic, V.; Arenz, M.; Markovic, N. M.; Ross, P. N. Oxygen Electrocatalysis in Alkaline Electrolyte: $\mathrm{Pt}(\mathrm{hkl}), \mathrm{Au}(\mathrm{hkl})$ and the Effect of Pd-Modification. Electrochim. Acta 2002, 47, 3765-3776.

(136) Gorlin, Y.; Chung, C.-J.; Nordlund, D.; Clemens, B. M.; Jaramillo, T. F. Mn 3 O 4 Supported on Glassy Carbon: An Active Non-Precious Metal Catalyst for the Oxygen Reduction Reaction. ACS Catal. 2012, 2, 2687-2694.

(137) Alexeyeva, N.; Tammeveski, K. Electrochemical Reduction of Oxygen on Multiwalled Carbon Nanotube Modified Glassy Carbon Electrodes in Acid Media. Electrochem. SolidState Lett. 2007, 10, F18. 
(138) Jürmann, G.; Schiffrin, D. J.; Tammeveski, K. The pH-Dependence of Oxygen Reduction on Quinone-Modified Glassy Carbon Electrodes. Electrochim. Acta 2007, 53, 390-399.

(139) Taylor, R. J.; Humffray, a. a. Electrochemical Studies on Glassy Carbon Electrodes III. $J$. Electroanal. Chem. Interfacial Electrochem. 1975, 64, 85-94.

(140) Gyenge, E. L.; Oloman, C. W. The Surfactant-Promoted Electroreduction of Oxygen to Hydrogen Peroxide. J. Electrochem. Soc. 2005, 152, D42-D53.

(141) Gyenge, E. L.; Oloman, C. W. Influence of Surfactants on the Electroreduction of Oxygen to Hydrogen Peroxide in Acid and Alkaline Electrolytes. J. Appl. Electrochem. 2001, 31, 233-243.

(142) Stamenković, V.; Schmidt, T. J.; Ross, P. N.; Marković, N. M. Surface Composition Effects in Electrocatalysis: Kinetics of Oxygen Reduction on Well-Defined Pt3Ni and Pt3Co Alloy Surfaces. J. Phys. Chem. B 2002, 106, 11970-11979.

(143) Machado, S. A. S.; Tanaka, A. A.; Gonzalez, E. R. Underpotential Deposition of Lead on Polycrystalline Platinum and Its Influence on the Oxygen Reduction Reaction. Electrochim. Acta 1994, 39, 2591-2597.

(144) El-Deab, M. S.; Ohsaka, T. Electrocatalysis by Nanoparticles: Oxygen Reduction on Gold Nanoparticles-Electrodeposited Platinum Electrodes. J. Electroanal. Chem. 2003, 553, $107-115$.

(145) Vaik, K.; Sarapuu, A.; Tammeveski, K.; Mirkhalaf, F.; Schiffrin, D. J. Oxygen Reduction on Phenanthrenequinone-Modified Glassy Carbon Electrodes in $0.1 \mathrm{M} \mathrm{KOH.} J$. Electroanal. Chem. 2004, 564, 159-166. 
(146) Alia, S. M.; Duong, K.; Liu, T.; Jensen, K.; Yan, Y. Supportless Silver Nanowires as Oxygen Reduction Reaction Catalysts for Hydroxide-Exchange Membrane Fuel Cells. ChemSusChem 2012, 5, 1619-1624.

(147) Quaino, P.; Luque, N. B.; Nazmutdinov, R.; Santos, E.; Schmickler, W. Why Is Gold Such a Good Catalyst for Oxygen Reduction in Alkaline Media? Angew. Chemie - Int. Ed. 2012, $51,12997-13000$.

(148) Ledezma-Yanez, I.; Wallace, W. D. Z.; Sebastián-Pascual, P.; Climent, V.; Feliu, J. M.; Koper, M. T. M. Interfacial Water Reorganization as a $\mathrm{pH}-$ Dependent Descriptor of the Hydrogen Evolution Rate on Platinum Electrodes. Nat. Energy 2017, 2, 17031.

(149) Hansen, M. H. H.; Nilsson, A.; Rosmeisl, J. Modelling pH and Potential in Dynamic Structures of the Water/Pt(111) Interface on the Atomic Scale. Phys. Chem. Chem. Phys. 2017, 19, 23505-23514.

(150) Merle, G.; Wessling, M.; Nijmeijer, K. Anion Exchange Membranes for Alkaline Fuel Cells: A Review. J. Memb. Sci. 2011, 377, 1-35.

(151) Seidel, Y. E.; Schneider, A.; Jusys, Z.; Wickman, B.; Kasemo, B.; Behm, R. J. Mesoscopic Mass Transport Effect in Electrocatalytic Processes. Faraday Discuss. 2008, 140, 167-184.

(152) Chen, S.; Kucernak, A. Electrocatalysis under Conditions of High Mass Transport Rate: Oxygen Reduction on Single Submicrometer-Sized Pt Particles Supported on Carbon. J. Phys. Chem. B 2004, 108, 3262-3276.

(153) Muthukrishnan, A.; Nabae, Y.; Okajima, T.; Ohsaka, T. Kinetic Approach to Investigate the Mechanistic Pathways of Oxygen Reduction Reaction on Fe-Containing N-Doped 
Carbon Catalysts. ACS Catal. 2015, 5, 5194-5202.

(154) Stephens, I. E. L.; Rossmeisl, J.; Chorkendorff, I. Toward Sustainable Fuel Cells. Science (80-. ). 2016, 354, 1378-1379.

(155) Kongkanand, A.; Mathias, M. F. The Priority and Challenge of High-Power Performance of Low-Platinum Proton-Exchange Membrane Fuel Cells. J. Phys. Chem. Lett. 2016, 7, $1127-1137$.

(156) King, D.; Browne, J.; Layard, R.; Donnell, G. O.; Rees, M.; Stern, N.; Turner, A. A Global Apollo Programme To Combat Climate Change; 2015.

(157) She, Z. W.; Kibsgaard, J.; Dickens, C. F.; Chorkendorff, I.; Nørskov, J. K.; Jaramillo, T. F. Combining Theory and Experiment in Electrocatalysis: Insights into Materials Design. Science (80-. ). 2017, 355, eaad4998.

(158) Lee, B.; Hibino, T. Efficient and Selective Formation of Methanol from Methane in a Fuel Cell-Type Reactor. J. Catal. 2011, 279, 233-240.

(159) Yamanaka, I. Active Control of Catalysis and Product Selectivity by a Fuel Cell System. Res. Chem. Intermed. 2006, 32, 373-385.

(160) Funakawa, A.; Yamanaka, I.; Takenaka, S.; Otsuka, K. Selectivity Control of Carbonylation of Methanol to Dimethyl Oxalate and Dimethyl Carbonate over Gold Anode by Electrochemical Potential. J. Am. Chem. Soc. 2004, 126, 5346-5347.

(161) Figueiredo, M. C.; Trieu, V.; Eiden, S.; Koper, M. T. M. Spectro-Electrochemical Examination of the Formation of Dimethyl Carbonate from CO and Methanol at Different 
Electrode Materials. J. Am. Chem. Soc. 2017, 139, 14693-14698.

(162) van der Ham, C. J. M.; Koper, M. T. M.; Hetterscheid, D. G. H. Challenges in Reduction of Dinitrogen by Proton and Electron Transfer. Chem. Soc. Rev. 2014, 43, 5183.

(163) Singh, A. R.; Rohr, B. A.; Schwalbe, J. A.; Cargnello, M.; Chan, K.; Jaramillo, T. F.; Chorkendorff, I.; Nørskov, J. K. Electrochemical Ammonia Synthesis-The Selectivity Challenge. ACS Catal. 2017, 7, 706-709. 
Graphic for Table of Contents (TOC)

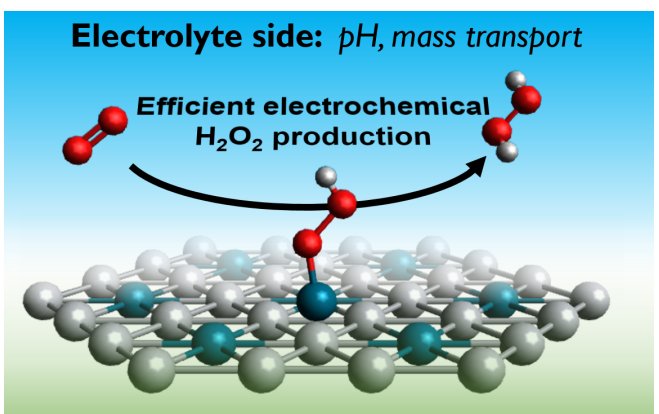

Electrode side: Electronic \& geometric effects 